\title{
A Systematic Literature Review on 30 Years of Empirical Research on Information Systems Business Value
}

\author{
Ahad ZareRavasan, Masaryk University, Czech Republic \\ Michal Krčál, Masaryk University, Czech Republic
}

\begin{abstract}
Information systems business value (ISBV) has been a key research topic for the IS research community. While the vast majority of ISBV research demonstrates the positive relationship between IS and firm performance, the fundamental question of the causal relationships between IS and business value remains partly unexplained. Moreover, researchers do not share a unified understanding of ISBV concepts. Therefore, this research intends to synthesize the past 30 years of empirical ISBV research, identify the gaps and shortcomings, conceptualize the ISBV concepts, and propose possibilities for further research that will widen the current narrowly-shared ISBV bottom line. The authors aim to synthesize (1) different operationalization of concepts in existing ISBV research; (2) IS determinants, consequences, and the relations among the variables; (3) the role of contextual factors; and (4) the adopted theoretical views.
\end{abstract}

\section{KEYWORDS}

Information Systems Business Value (ISBV), Information Systems Capabilities, Information Systems Investment, Information Systems Use, Systematic Literature Review (SLR)

\section{INTRODUCTION}

The Information Systems ${ }^{1}$ Business Value (ISBV) has been one of the major research topics for IS researchers. ISBV is "the impact of investments, particularly IS assets on the multidimensional performance and capabilities of economic entities at various levels, complemented by the ultimate meaning of performance in the economic environment" (Schryen, 2013, p. 141). ISBV commonly refers to the impacts of IS, at both the intermediate process level and the organization-wide level, and comprises of efficiency and competitive impacts (Melville et al., 2004). Early ISBV empirical studies and popular Harvard Business Review article by Carr (2003), entitled "IT doesn't matter," were doubting ISBV (e.g., Hitt \& Brynjolfsson, 1996; Hu \& Plant, 2001; Weill, 1992). Gradually, arguments supporting the existence of ISBV have been observed (e.g., Kohli \& Devaraj, 2004; Lee et al., 2015; Santhanam \& Hartono, 2003). Early ISBV research has predominantly targeted the direct positive relationship between IS and firm performance (e.g., Barua et al., 1995; Mahmood \& Mann, 1993a; Marshall \& Byrd, 1997). Even though later research attempted to provide evidence about ISBV creation mechanisms (e.g., the effect of IS on business processes (e.g., Dehning et al., 2007; Shahzad et al., 2020), decision making performance (e.g., Aydiner et al., 2019; Mishra et al., 2018; Yichuan Wang \& Byrd, 2017), or strategic orientation (e.g., Aydiner et al., 2019; Yeh et al., 2012)) and thus "unlocking the gray box", it is not covered sufficiently in the history of ISBV research (Schryen,

\section{DOI: $10.4018 / J G I M .288894$}

This article published as an Open Access article distributed under the terms of the Creative Commons Attribution License (http://creativecommons.org/licenses/by/4.0/) which permits unrestricted use, distribution, and production in any medium, provided the author of the original work and original publication source are properly credited. 
2013). Despite this, based on our review, the basket of eight IS journals have published only 18 ISBV papers during the last decade. Schryen (2013) believes that the general decreasing attention to the ISBV topic is not rooted in any declining interest on the journals' side, but is based on the declining activities of ISBV researchers. Providing new perspectives in the ISBV domain through fresh literature reviews can reactivate researchers' interests and activities by highlighting the research gaps. This is very important in the ISBV domain as the ISBV research body is unbalanced.

On the one hand, some aspects of ISBV have been over-researched. For instance, even though it is well established in the recent literature that IS measures do not directly affect firm performance, most ISBV literature is dedicated to examining this relationship (Schryen, 2013). On the other hand, several aspects of the causal relationship between IS and business value and the mechanisms through which IS creates business value remain partially unaddressed. For instance, according to Schryen (2013, p. 149), "the particular relationships between IS assets and complementary capabilities, their roles in the value generation process, and the conditions under which competitive value is created remain unclear." The effect of the time lag between IS investment and created business value and the role of different IS, management, and organizational theories while investigating ISBV research are also less explored areas (Rajiv Sabherwal \& Jeyaraj, 2015).

This imbalance of focus on ISBV research calls for further and detailed investigation to synthesize the concepts and studied relations. As a contribution of this research, and based on the proposed synthesized ISBV model (see Figure 2), it shows how and which concepts, relations, and theoretical views are (over)researched, which relations showed consistent or inconsistent results, and which concepts and relations need to be put into the spotlight. Then, our research will provide a detailed summary of used variables and underlying theoretical views in prior ISBV research together with conceptualization, and it will lead to the unification of measures in future studies. Particularly, this study builds on the lack of detailed answers in the existing research on the following questions:

RQ1: How are constructs related to ISBV operationalized in the literature?

RQ2: What are the IS variable's determinants?

RQ3: How do IS contribute to ISBV (IS investment consequences: process and firm performance)? RQ4: What Contextual factors play a role in creating ISBV?

RQ5: What theoretical views are adopted in ISBV research?

To answer these research questions, we need to define the scope and focus of this research. Considering suggestions by Dehning and Richardson (2002) on choosing a level of examination and the approach proposed in Schryen (2013), we distinguish our review in terms of the level of evaluation, time of evaluation, and object of evaluation. The distinction allowed us to concentrate on the research that focuses primarily on ISBV creation.

- Level of evaluation: ISBV research includes conceptual, theoretical, analytic, and empirical studies (Melville et al., 2004). We focus only on empirical studies (qualitative research, case studies, field studies, and quantitative studies). Besides, ISBV can be investigated at different analysis levels, such as individual, firm, industry, and economy (also known as country or macro) (Chau et al., 2007). We limit our scope to the firm-level ISBV because this helps control the problems associated with aggregations at the industry level (Brynjolfsson \& Yang, 1996).

- Time of evaluation: Research on ISBV can be of ex-ante and ex-post nature. Ex-ante evaluation of ISBV addresses which of the available IS investment options will best benefit the firm. On the other hand, ex-post research investigates the extent to which IS has created value (Kohli \& Grover, 2008). We adopted the second view. Besides, ISBV can be realized immediately (such as abnormal stock price fluctuations because of market reactions to some announcements or events within a few days) and non- immediately (year(s)). This paper focuses on the non-immediate aspect only. 
- The object of evaluation: ISBV can be studied having an overall view on IS variable (i.e., IS investment, IS capabilities, IS resources, IS staff, and IS use). We cover all views in our review. Besides, we investigate IS variable determinants, which consider IS variable as a dependent variable.

Based on these, we define the scope of this literature review in Figure 1. It shows the procedure of narrowing the research topic down that is also used to filter and exclude papers later in the screening process. The "level of evaluation" part of the figure shows that we are only interested in empirical research that can be conducted at four levels, but we focus on firm-level studies. Then, at the "time of evaluation", we only opt to review ex-post studies with non-immediate ISBV effects. As can be observed from the "object of evaluation" part of the figure, non-immediate effects can be direct or indirect with different measurement items. Besides, this study covers the IS determinants that will be discussed later in detail.

For the rest of this paper, firstly, we review prior ISBV literature reviews in the next section. Then, we develop an ISBV model that systematizes and extends accumulated knowledge. We present the Systematic Literature Review (SLR) methodology afterward. The following section represents the findings, followed by future research suggestions. The final section concludes the paper.

Figure 1. The scope of this ISBV literature review (inclusion/exclusion criteria)

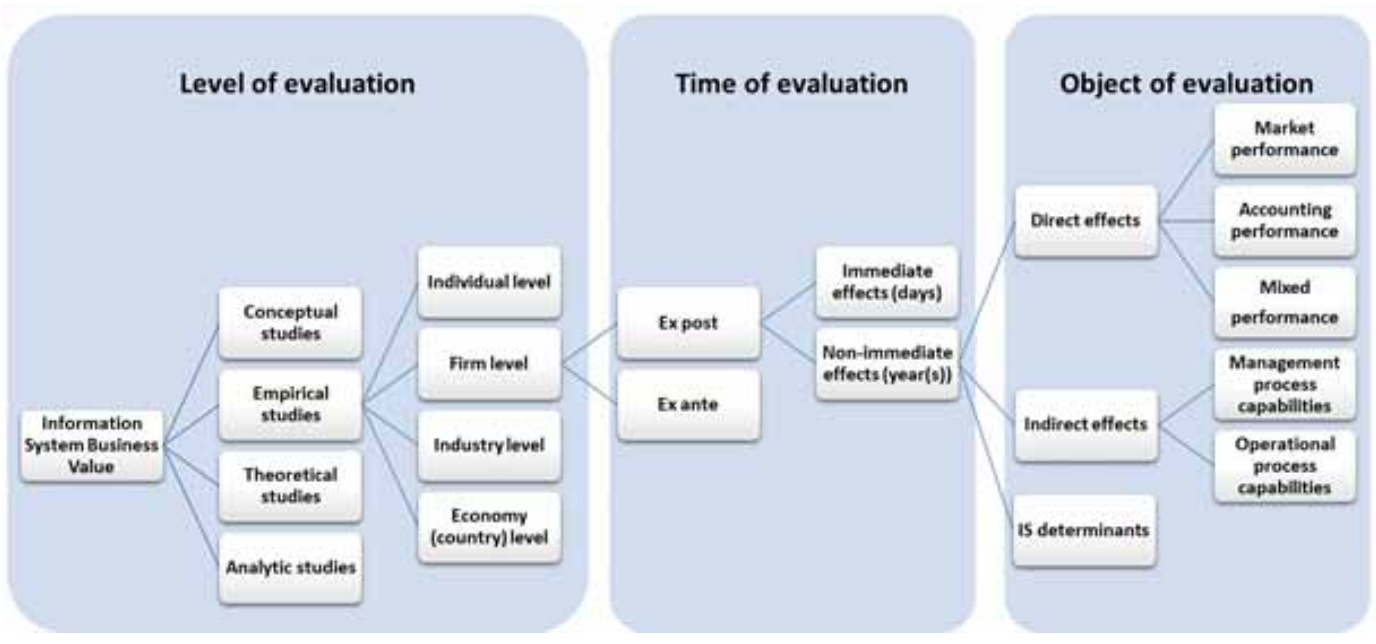

\section{PRIOR ISBV LITERATURE REVIEWS}

This section examines ISBV literature reviews that investigated the relationship between relevant independent IS variables (i.e., IS investment, IS capabilities, IS assets, and IS use) and dependent performance variables (i.e., process performance or firm performance). Examining the reviews helped us increase our sensitivity to evaluate the relevancy of potential papers that needed to be included in our sample in later steps of our SLR.

Among the first literature review studies, Kauffman and Weill (1989) review 13 empirical studies published in 1975-1988. Drawing on economics and behavioral science, the authors investigate motivation (purpose, approach, theory base), focus (unit of analysis, locus of value, the role of system performance), and caveats (measures, data analysis, organizational context). Brynjolfsson (1993) focuses on 18 studies investigating IS investments' impact on productivity in the economy, 
manufacturing, and services. He suggests that the shortfall of IS productivity is due to deficiencies in measurement and methodology. Brynjolfsson and Yang (1996) update the earlier review of Brynjolfsson (1993) by classifying 46 IS productivity studies into economy-wide, industry-level, firm-level, consumer surplus, and economic growth. This study's key findings encompass those already proposed in Brynjolfsson (1993). However, it provides more detailed elaboration on the four types of deficiencies: measurement errors, lags, redistribution, mismanagement, how they affect the results, and how they can be treated. Soh and Markus (1995), synthesizing five prior ISBV models, proposed a new ISBV model incorporating the IS conversion process, IS use process, and competitive process. Chan (2000) classifies ISBV studies according to research methods (e.g., survey, secondary data, and case study), measures (financial and non-financial), and levels of analysis (e.g., individual, organizational, national).

Dehning and Richardson (2002) propose a framework to classify ISBV empirical studies regarding the impact of IS variable (spending, strategy, and management/capability) on performance. Performance measures are further decomposed into process measures (e.g., inventory turnover, customer service, quality) and firm performance (marketing and accounting oriented) measures. Dedrick et al. (2003) propose a production system framework to review empirical studies based on economic analysis. To address the productivity paradox, they present three analysis levels: firm, industry, and country. Kohli and Devaraj (2003) review 66 firm-level ISBV papers through a metaanalysis to examine IS payoff determinants. Employing logistic regression and discriminant analyses, they present statistical evidence of the characteristics that discriminate between IS payoff studies that observed a positive effect and those that did not. Melville et al. (2004) review 202 ISBV papers and develop a resource-based ISBV model incorporating the firm, industry, and country environment. Melville et al. (2004, p. 298) use this model to develop the following research questions: "(1) is the IS resource associated with improved operational efficiencies or competitive advantage, and how? (2) what is the role of industry and country characteristics in shaping ISBV? (3) what is the role of electronically linked trading partners' resources and business processes in impacting the value generated and captured by the focal firm?"

Piccoli and Ives (2005) synthesize ISBV literature that examines IS role in sustaining competitive advantage. They propose a theoretical framework that relates response-lag drivers to erosion barriers, and from there, to sustained competitive advantage moderated by the competitive environment. Chau et al. (2007) investigate ISBV papers published in ECIS or PACIS. They propose a two-dimensional taxonomy: (1) ISBV dimensions (use satisfaction, individual impact, organizational impact, and societal impact), and (2) issues in measuring ISBV (stakeholder, type of IS asset, unit of analysis, type of data, and research method). However, the range of analyzed papers is limited to studies published in ECIS or PACIS proceedings and does not include journal papers.

Wan et al. (2007) analyze 96 papers from 1996 to 2006 that cite Brynjolfsson and Hitt's (1996) paper. They classify empirical research by their results (positive, negative, no effect, or contingent), level of analysis (individual, process, firm, industry, multi-level), research methods (secondary data, survey, case study, others, multi methods), and variables included in the model (inputs, complementary factors, process, intermediate outputs, and outcomes). Kohli and Grover (2008, pp. 25-27) review ISBV literature at the firm level. They present seven statements describing what we know as "(1) IS does create value (2) IS creates value under certain conditions (3) IS-based value manifests itself in many ways (4) IS-based value is not the same as IS-based competitive advantage (5) IS-based value could be latent (6) numerous factors are mediating ISBV, and (7) causality of IS value is elusive". Pare et al. (2008) classify empirical research papers according to which method and purpose they follow, whether they use variance theories or process theories, whether they adopt a technological imperative, an organizational imperative, or an emergent perspective.

Liang et al. (2010) aggregate previous research that adopts the Resource-Based View (RBV) to examine ISBV. They develop a framework that includes direct and indirect effects and conduct a meta-analysis on 42 published empirical studies to examine how different factors in the RBV 
affect firm performance. Lim et al. (2011) use meta-analysis to examine ISBV research focusing on IS investment's return. Specifically, they consider five primary issues in their meta-analysis and highlight the difference between their work and prior similar work of Kohli and Devaraj (2003). The key areas are: (1) the relation between IS investment, and firm performance, (2) IS investment measurement issues, (3) firm performance measurement issues, (4) experimental design and other variable measurement issues, and (5) covariate and control variable selection issues.

Masli et al. (2011) synthesize recent empirical ISBV research and examine (1) financial and non-financial measures, (2) IS investment measures and links with firm performance, (3) IS and business complementarities that affect firm performance, and (4) the impact of business context and IS alignment with the business strategy on resulting performance. They also propose a balanced scorecard framework that places IS in a business context and highlights the role of potential drivers and contextual factors. Schryen (2013) presents a literature review (covering ISBV research since 1989) and proposes a new ISBV model. He summarizes findings of prior research in six areas as (1) Performance measures, (2) Impact on productivity, (3) Impact on market performance, (4) Impact on accounting performance, (5) Contextual factors, and (6) Lag effects. He concludes with three main research gaps, research thrusts, and research paths.

The most recent published ISBV is the work of Sabherwal and Jeyaraj (2015). They extend Kohli and Devaraj's (2003) work by meta-analyzing 303 ISBV studies published between 1990 and 2013. They investigate (1) whether each measured IS investment, (2) Study's methodological attributes (i.e., sample size; secondary versus primary data, regression versus other techniques, number of IS-based antecedents; and number of dependent variables), (3) value generation (i.e., IS assets, IS adoption or use; and IS infrastructure or capability), (4) value measures (i.e., profitability and productivity), (5) value enablers (i.e., IS progress and developing region), (6) moderating effects, and (7) theoretical approaches (i.e., technological, organizational, or environmental theories).

More details regarding the ISBV literature reviews can be found in Schryen (2010). He has conducted a comprehensive literature search and a meta-review analysis to determine the extent to which past ISBV literature reviews have covered main research areas. The areas are terminology, performance measure (productivity, market performance, accounting performance, intangible benefits), level of measurement, type of IS asset, methods, influencing factors (contextual factors, lag effects, risks), and value. A summary of the review period, sample size, and key findings of prior ISBV literature reviews are illustrated in Appendix I.

\section{THE PROPOSED FRAMEWORK FOR EVALUATING ISBV LITERATURE}

We develop a new ISBV conceptual model (see Figure 2) based on a synthesis of prior ISBV models (see Appendix I). Our approach to synthesizing these models was to keep their shared understanding of ISBV and then extend the model by incorporating new aspects that could be useful in elaborating ISBV more appropriately. Therefore, we started with the overlap between the models summarized in the following statements:

- IS variable can be investigated in different forms, such as IS investment (or IS expenditures, IS spending, IS budget), IS capabilities (e.g., human, managerial, technical), and IS use.

- IS measures directly or indirectly (through process performance) impact firm performance (e.g., market and accounting performance measures).

- ISBV is affected by contextual/environmental factors on the firm, industry, and country levels.

Then, we considered several aspects that were mentioned by individual authors and incorporated them into the new model to make it more illustrative.

- Based on Schryen (2013), we included time lags into our model, which authors have not considered in the other models. 
- Schryen's (2013) model includes 'IS investment' as a category and not an independent variable influencing performance. Adopted from Dehning and Richardson (2002), we included 'IS investment' to 'IS measures.' It allowed us to study the consequences of 'IS investment' more precisely.

- Wade and Hulland (2004) see 'IS resources' as 'IS assets' and 'IS capabilities.' However, in light of IS capabilities definition as a firm's ability to acquire, deploy, combine, and reconfigure IS resources in support and enhancement of business strategies and work processes (Lu \& Ramamurthy, 2011, p. 932), most research views 'IS assets' as a type of 'IS capability.' Therefore, to prevent confusion in the model and the coding process, we use 'IS capabilities' to refer to 'IS human capabilities,' 'IS management capabilities' and 'IS assets' of Schryen's (2013) original model.

- We introduce a new construct as 'IS use' that refers to IS use and adoption at the firm level (Sabherwal \& Jeyaraj, 2015). Accordingly, our proposed 'IS measures' category incorporates 'IS investment,' 'IS capabilities,' and 'IS use.'

- IS can influence intermediate business processes and create business value. Schryen's (2013) model incorporates such intermediate business processes but does not go deeper into different processes. Adopted from Radhakrishnan et al. (2008), we argue that business processes include operational and management processes. Management processes match the "process planning and support," and operational processes match the "supplier relations, production and operations, product and service enhancement, sales and marketing, and customer relations" categorization of business processes by Tallon et al. (2000) and Gu and Jung (2013). We code process performance measures by "management process capabilities" and "operational process capabilities" for simplicity.

- Firm performance is mainly assessed using accounting and market-based performance measures. However, some research (particularly surveys) used a mix of accounting and market measures. Given that, we introduce two new measures as "hybrid" in the firm performance measures level.

- The role of contextual factors (firm, industry, and country (macro) level) in ISBV is well highlighted. In line with Lu and Ramamurthy (2011), we argue that IS context (e.g., IS type, size, and age) also matters. Thus, we include 'IS level' as a new contextual factor in the model.

- Little is known about the determinants of 'IS measures,' but previous studies have not investigated that to close the loop. One such potential determinant could be performance feedback. For instance, positive feedback could positively or negatively affect subsequent IS investment (Baker et al., 2017). As another instance, pressure from competitors, suppliers, or customers might also impact subsequent IS investment (Ravichandran et al., 2009). In light of this, we include a new dimension as "IS measures determinants" in our ISBV model.

These key insights finally lead to the model shown in Figure 2. We used this model to answer the research questions and structure our literature review in the following sections. More specifically, RQs 2-4 are related to the paths (conceptualization) in the figure. RQ1 addresses the operationalization of constructs throughout the whole model, and RQ5 addresses the theories used to build the conceptual models in prior ISBV research. Further details on the underlying concepts and measurement issues of the terms within the figure will be provided in the findings section. Nevertheless, this research is distinguished from prior related research in two ways. First, as presented earlier in this section, the synthesized ISBV model in Figure 2 incorporates a new dimension as "IS measures determinants". It also encompasses detailed measures into "IS measures", "IS measures consequences" and "contextual factors". Second, this research goes beyond synthesizing a conceptual model and systematically addresses both conceptualization and operationalization issues of measures introduced in the model. It helps researchers to see which concepts and relations are examined, how they are treated in prior research and if there is a consensus on the findings among different empirical research.

\section{SYSTEMATIC LITERATURE REVIEW METHODOLOGY}

This research follows the SLR method proposed by Bano and Zowghi (2014), which comprises three steps: planning, execution, and reporting results. During the planning phase, we followed a formal protocol for conducting SLR. The protocol contained the details of our primary and secondary search 


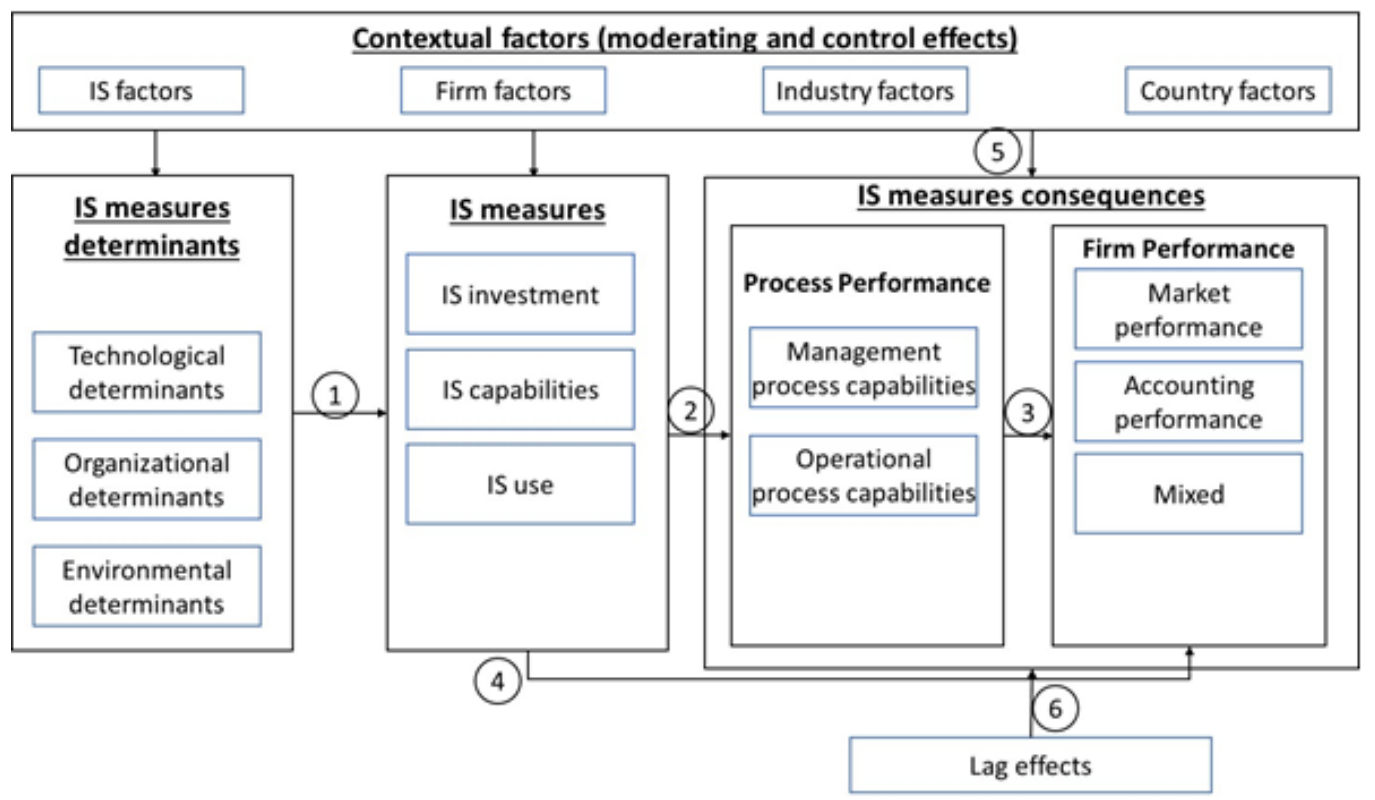

strategy, papers inclusion/exclusion criteria in the review, data extraction strategy, and data synthesis as follows.

\section{Primary Search Strategy}

We employed the Scopus search engine to discover the ISBV literature. The breadth of coverage, quality of data, and ease of extraction make Scopus an ideal choice for our SLR. To ensure that we included all relevant articles in our final dataset, the title, abstract, and keywords of the published papers in Scopus were searched using the following query. The query is run on August 2020 and updated on January 2021 to ensure covering all published papers of 2020 in the final dataset.

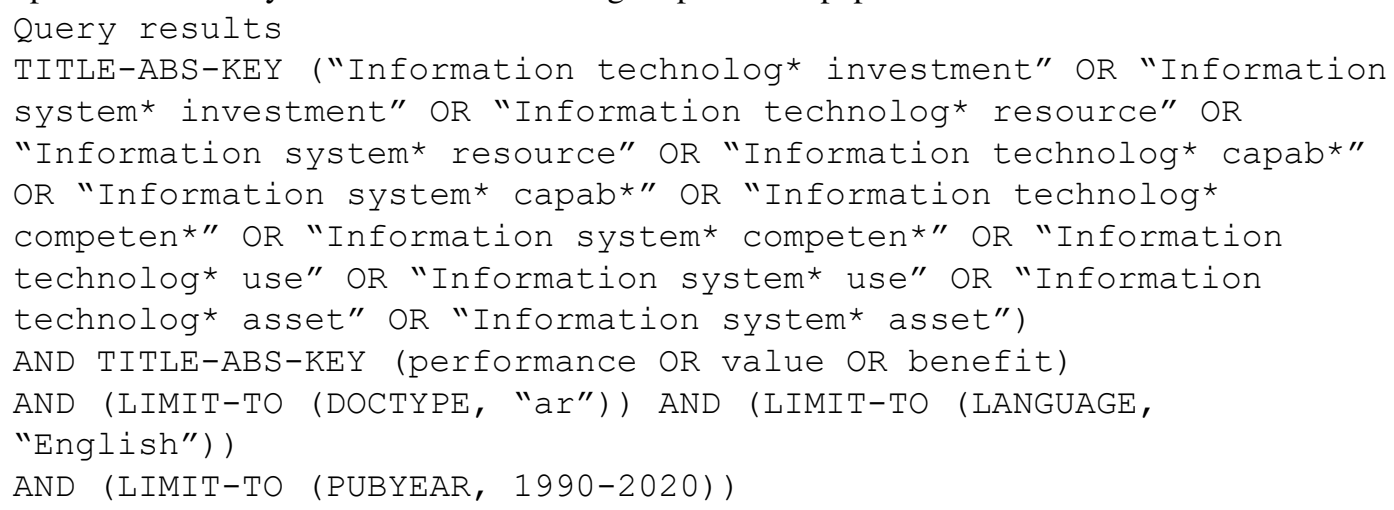

We only included journal articles published in English from 1990 to 2020 (there were only 11 papers till 1990, which is negligible). Furthermore, conference papers, textbooks, chapter books, and working papers were not included because academics and practitioners use journals to disseminate new findings (Hanafizadeh \& Zareravasan, 2020). 


\section{Secondary Search Strategy}

To ensure that we did not miss any relevant studies, we devised a secondary search strategy by scanning and reviewing all the references of 18 ISBV literature reviews (see Appendix I for the list of extant review papers). We need to highlight that we only included English journal articles indexed in Scopus by searching for their exact title. Needless to say that we did not include them if they are already available from the primary search.

\section{Sample}

Through the Scopus primary search, we reached a total number of 588 papers. The secondary search resulted in 174 new papers that were not included in the primary search results. Accordingly, our sample encompassed 762 papers. In the next step, publications were reviewed for inclusion criterion by reading title, abstract, and full text. Based on Figure 1, we include only firm-level empirical studies that examine the ex-post non-immediate ISBV effects. The effect could be direct or indirect. The irrelevant papers were excluded by reading the title, abstract, and when their relevancy was not conclusive from the abstract, we read the papers' full text. For instance, we excluded studies that investigated ISBV at a country level (e.g., Dedrick et al., 2013) or those that examined the immediate effects of IS investment (e.g., Chatterjee et al., 2002; Wijayana \& Achjari, 2019).

Moreover, regarding studies that investigated path 1 , we only included those that examined path 1 along with any other paths simultaneously. The reason is that we aim to model ISBV, and IS determinants have to finally lead to ISBV (IS measures consequences in Figure 2). For instance, we excluded Al-Shboul (2019) because he has only examined path 1 in the model. However, for instance, we included Weill's (1992) investigation of paths 1,4; investigation of paths 1, 4, 6 by Hu and Plant (2001); investigation of paths 1, 4, 5 by Bhatt and Grover (2005). Consequently, 235 papers were consistent with inclusion and exclusion criteria. Figure 3 illustrates the whole process.

\section{Data Synthesis And Analysis}

To respond to research questions, we used content analysis to code the content of the articles. We targeted three groups of data: articles' meta-data (e.g., publication date, and journal name), the context of the research (e.g., research method, sample, theoretical base), and finally, conceptualizations and operationalization related to the boxes in Figure 2 (e.g., dependent, and independent variables, operationalization, type of relations). More specifically, we are interested in the following items (see Appendix II for details): journal name, theories used in the model, industry sector, country, method-data (cross-sectional/longitudinal, primary/secondary source, sample), path (the type of the relationship between an independent and dependent variable), contextual factors (IS, firm, industry, and country-level factors), measuring value (objective, subjective), operationalization (how the variables are measured), type of relations (direct, indirect, or both), time lag (the lag from IS investment to performance realization), path mark (based on Figure 2).

We have used boxes in Figure 2, as our master codes and then assign the measurement items to them. For instance, we assigned "operating IS budget" (Wang et al., 2018), and "Firm's annual IS budget" (Havakhor et al., 2019) to IS investment. Likewise, we assigned ROA, and ROE to accounting performance measures. It should be noted that since scholars employed different names for the same terms, concepts, or factors, we needed to cautiously code the articles' content. We could not code the terms, concepts, or factors just according to their names in the reviewed papers but by the meaning and context of each term in the text. For instance, we have coded both "competition intensity" (Purnama \& Subroto, 2016) and "competitive environment" (Sriram \& Stump, 2004) as "competitive environment" since both terms refer to the same concept. Two authors conducted the codification process separately, with the results displayed in Appendix II. In case of conflicts, the authors discussed the views and reached a decision together. 


\section{Identification of studies via Scopus}

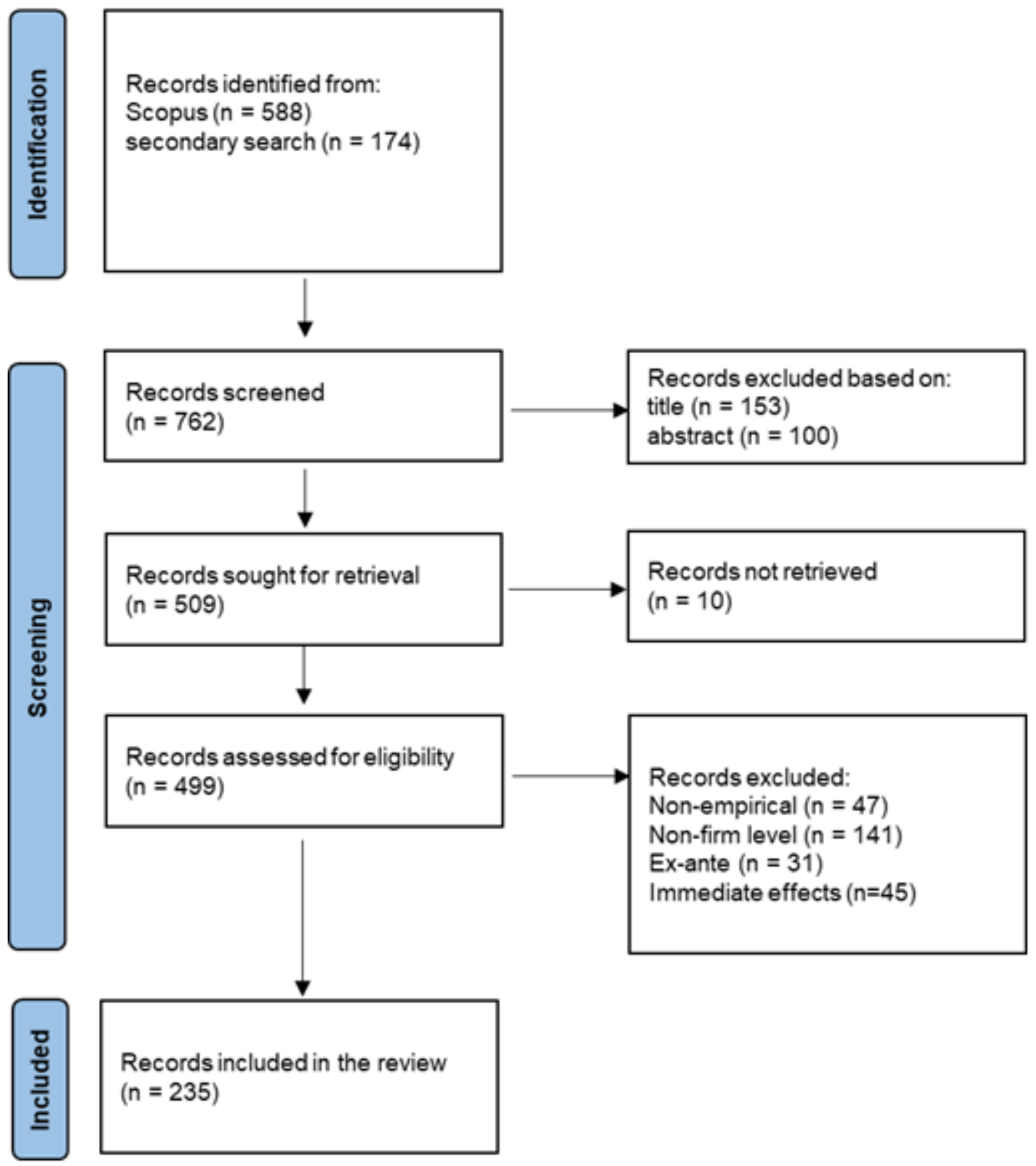

\section{FINDINGS}

This section presents the findings of our SLR in three subsections. The first subsection provides some descriptive information regarding the journals, industries, countries, the trend of publications, and data sources. The second subsection presents the findings related to the operationalization of our ISBV model's different constructs. Finally, the third subsection discusses the type of relationships (conceptualization) covered in prior ISBV research. The full records for the 235 reviewed papers and coded items are presented in Appendix II. 


\section{Descriptive Information}

A total of 99 journals published 235 ISBV papers from 2000 and 2020. Table 1 presents a list of the top 10 journals. These journals have published $46 \%$ of all the ISBV papers indicating the core outlet for ISBV research. The publication period data shows that some of these journals, such as I\&M, MISQ, and ISR are classic, yet dominant outlets. IJIM can be considered an emerging outlet with the first paper in 2008 and still interested in the ISBV topic. Some classic journals are not publishing ISBV research any longer, such as Management Science, Omega, and EINT.

Table 1. Top 10 journals published ISBV literature

\begin{tabular}{|c|c|c|c|}
\hline Journal & Frequency & Publication period & $\begin{array}{c}\mathbf{2 0 1 9} \\
\text { IF* }\end{array}$ \\
\hline Information and Management (I\&M) & 20 & $1995-2018$ & 5.155 \\
\hline Management Information Systems Quarterly (MISQ) & 19 & $1995-2019$ & 5.361 \\
\hline Journal of Management Information Systems (JMIS) & 16 & $1990-2012$ & 3.949 \\
\hline Information Systems Research (ISR) & 14 & $1992-2019$ & 3.585 \\
\hline Industrial Management and Data Systems (IMDS) & 9 & $2006-2014$ & 3.329 \\
\hline Management Science & 7 & $1994-2013$ & 3.931 \\
\hline Decision Support Systems (DSS) & 6 & $2000-2017$ & 4.721 \\
\hline Economics of Innovation and New Technology (EINT) & 6 & $1995-2005$ & 1.536 \\
\hline International Journal of Information Management (IJIM) & 6 & $2008-2019$ & 8.210 \\
\hline Omega & 6 & $1996-2008$ & 5.324 \\
\hline
\end{tabular}

* Source: clarivate.com

Figure 4 illustrates the trend of ISBV published papers throughout the period. It shows an increasing interest in the ISBV research domain from 2004, with a peak in 2012 following a sudden decline and slow increase, peaking in 2019. The decline in 2020 can be a sign of another downward change of trend, however, the explanation will be possible in several years. The first decline in publications focusing on ISBV could have been caused by introducing new topics. One such a topic overlapping with ISBV could be digital transformation which increased severely in popularity around 2018. Out of 1956 documents in SCOPUS containing digital transformation in the title, only 299 were published prior to 2018. The reason for a potential decline in 2020 could be caused by the shift in topics following the COVID-19 pandemic.

We also depict each country's share in the published papers based on the data source (and not based on the authors' affiliated countries) in Figure 5. For instance, if an Indian researcher or a group of international researchers used US-based firms' data for their analysis, it is labeled as the USA. Similarly, if the dataset encompasses multi-national firms' data, it is labeled as multi-national, regardless of the authors' affiliation.

The USA's first rank could be explained by the access to different commercial secondary sources of panel data for IS measures such as IDG's ComputerWorld and InformationWeek 500 (IW500) that ISBV researchers adopted most frequently.

Cross-sectional studies based on primary data (such as surveys and case studies, coded as C-P in Appendix II) and longitudinal studies based on secondary data (such as IW500, coded as L-S in Appendix II) accounted for the majority of data sources with $46 \%$ and $44 \%$, respectively. Besides, only $6 \%$ of papers used cross-sectional studies based on secondary data (C-S in Appendix II), and there was no research built upon a longitudinal and primary data source. 


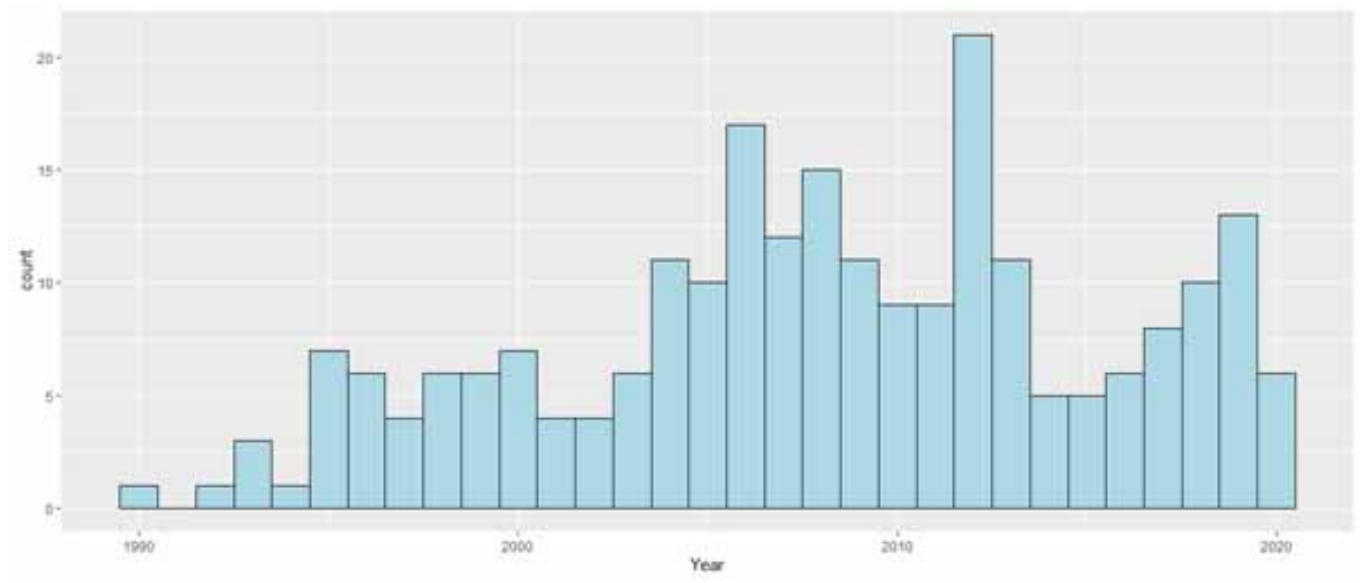

Figure 5. The share of each country in the published papers

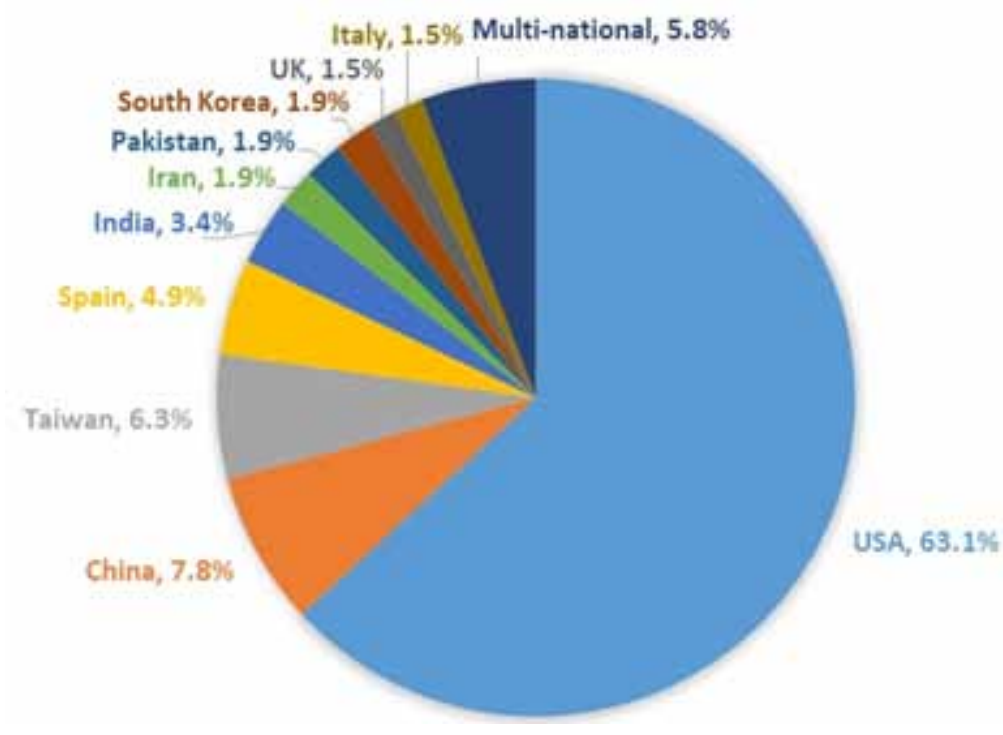

Furthermore, nearly $62 \%$ of the studies covered multiple sets of industries in their dataset. The rest have limited their datasets to a single industry context, leading with manufacturing $(12.8 \%)$, followed by healthcare (6.8\%), financial (5.5\%), and retail (3.4\%).

\section{Operationalization of ISBV Model's Elements}

This section addresses RQ1, focusing on different approaches to operationalize the ISBV constructs (IS determinant, IS measures, process performance, and firm performance).

\section{IS Measures Determinants}

We adopt the technology, organization, and environment (TOE) framework to categorize different types of IS measures determinants. This framework has been proposed by Tornatzky et al. (1990) 
to explain the process of innovation in the context of an enterprise. It considers three features of an enterprise that influence the adoption of innovation. The technology context refers to the internal and external technology relevant to the organization and the available technologies for possible adoption. The organization context refers to the descriptive characteristics of a firm. Formal and informal linking, structures, communication processes, size, and slack suggested by Tornatzky et al. (1990) are factors that influence adoption in the organization aspect. The environment context is comprised of the market elements, competitors, and the regulatory environment. Tornatzky et al. (1990) proposed industry characteristics and market structure, technology support infrastructure, government regulation as the factors that influence adoption in the environmental aspect. TOE has been selected here to cover a broad set of factors affecting IS measures simultaneously that can be classified in the TOE contexts.

IS determinants are dominated primarily by the organizational and environmental categories. Prior firm performance in light of the behavioral theory of the firm is used in Weill (1992) and Salge et al. (2015). According to the behavioral theory of the firm, senior managers will search for alternatives to the current set of activities whenever they consider the performance of their organization unsatisfactory. This theory suggests that a search mechanism stimulated by a problem and is directed toward finding a solution can be triggered, known as problemistic search (Salge et al., 2015). In addition to prior firm performance, managers routinely evaluate the level of uncommitted resources in their organization. When resources are viewed as being in surplus, they will seek to identify promising investment opportunities, a process known as slack search. We code this search mechanism as financial slack that is adopted in Sabyasachi (2005) and Salge et al. (2015). Other commonly used organizational level IS determinants include entrepreneurial orientation (Sun et al., 2019; Zhang et al., 2013), technology orientation (Hao \& Song, 2016; Trainor et al., 2011), marketing orientation (Trainor et al., 2011; Zhang et al., 2013), and organizational learning orientation (Bhatt \& Grover, 2005; Zhang et al., 2013).

Environmental level IS determinants range from macro to industry-level variables. Environmental uncertainty (Kobelsky et al., 2008; Purnama \& Subroto, 2016; R. Sabherwal et al., 2019; Zhang et al., 2013) and regulative legitimacy (Salge et al., 2015) are among the macro-level environmental factors. At the industry level, industry concentration (Kobelsky et al., 2008), competitive environment (Purnama \& Subroto, 2016; Sriram \& Stump, 2004), competitors' IS intensity (Kobelsky et al., 2008; Purnama \& Subroto, 2016; Ravichandran et al., 2009; Salge et al., 2015), customers' IS intensity (Ravichandran et al., 2009) and suppliers' IS intensity (Ravichandran et al., 2009) are used as factors determine IS measures.

\section{IS Measures}

We label IS measures as IS investment, IS capabilities, and IS use. IS investment is measured differently in the reviewed literature, more specifically in the longitudinal empirical research. IS annual budget (also known as IS spending, IS expenditures) (e.g., Baker et al., 2008; Havakhor et al., 2019; Peslak, 2003; Walsh et al., 2010) is the most frequently used variable to measure the magnitude of IS investment. Other approaches include IS capital (e.g., Barua et al., 1995; Kleis et al., 2012; Tam, 1998), IS capital scaled to total assets (e.g., Chowdhury, 2006; Dewan \& Ren, 2011; Xue et al., 2012), IS budget scaled to sales or revenue (e.g., S. Aral \& Weill, 2007; J. K. Kim et al., 2009; Mithas et al., 2016), IS budget scaled to total operating costs (e.g., Thouin et al., 2008), IS budget per employee (e.g., Mithas et al., 2012; Ray et al., 2005), and IS capital per employee (e.g., Bloom et al., 2012). There are also few other studies examining the effect of IS investment announcements on the long-term business value (Dehning et al., 2007; Ji et al., 2019; Otim et al., 2012).

IDG's ComputerWorld and IW500 are the most cited sources to collect firm-level IS investment data. Compustat database is typically used to estimate IS investment-related ratios such as IS budget scaled to financial indexes such as sales or revenue. Compustat's other typical use is to estimate combined indices such as IS capital scaled to total assets and IS budget scaled to sales or revenue. 
However, IDG's ComputerWorld and IW500 only cover firms located in the USA. Furthermore, IS investment does not necessarily indicate the efficiency and effectiveness of a firm's IS capability (Masli et al., 2011). That is probably why some authors prefer to use IS capabilities rather than IS investment in their model.

The concept of 'IS capabilities' in longitudinal studies is mainly operationalized using IT leadership rankings reported in commercial databases such as IW500 (e.g., Chae et al., 2018; Dale Stoel \& Muhanna, 2009) or CIO Magazine ranking (e.g., Adi Masli et al., 2011) for the USA, or similar datasets in other countries such as Informatics 500 (e.g., Wu et al., 2017) in China or CIO India Magazine ranking (e.g., Arora \& Rahman, 2017) and CMIE Prowess database (Thakurta \& Guha Deb, 2018) in India. Studies relying on primary data sources operationalized 'IS capabilities' very differently. Some authors view it as a simple first-order construct. For instance, Chen (2012) operationalized 'IS capabilities' as human IS resources, and Irfan and Wang (2019) as flexible IT resources. Nevertheless, other scholars adopt 'IS capabilities' as a second-order construct. For instance, Yeh et al. (2012) differentiated it at the individual level capability (IS leadership capability, IS resource allocation capability), group-level capability (collaboration capability, Knowledge sharing capability), and organization level capability (system development capability, project management capability). Different aspects of 'IS capabilities' such as IS infrastructure or IS technical assets (e.g., Aydiner et al., 2019; Y. Chen et al., 2015; Lyver \& Lu, 2018), IS human capabilities (e.g., Cohen \& Olsen, 2013; Phama \& Jordanb, 2009), IS management capabilities (e.g., Benitez-Amado et al., 2010; Tallon, 2008), and IS and business alignment capability (e.g., Tallon et al., 2000) were adopted in the literature to measure this construct.

The concept of 'IS use' is the third category of IS measures. Some studies adopted 'IS use' as a proxy of IS measures to assess ISBV in cross-sectional studies using primary data sources. While early studies measured the use intensity of general and basic technologies such as EDI, Internet, intranet, fax, and email (e.g., Andersen \& Segars, 2001; Grover et al., 1998; Johannessen et al., 1999), later research adopted more specific IT tools and applications such as e-commerce (Kraemer et al., 2005), computer-aided manufacturing and design (L. Li, 2005; Macher \& Mowery, 2009), decision support systems (Kohli \& Devaraj, 2004), CRM and SCM (Hyvönen, 2007; Y. Li \& Huang, 2012), and business analytics (e.g., Ashrafi et al., 2019; Ghasemaghaei et al., 2017). Some other authors such as Sánchez-Rodríguez et al. (2006) surveyed 'IS use on different organizational and process levels such as IT for top management, IT for customer relations, IT for supplier relations, IT for workforce management, IT for product design, IT for process flow, and IT for quality.

\section{IS Measures Consequence: Process Performance}

We adopt two broad categories of process performance, including operational and management process capabilities, as Radhakrishnan et al. (2008) suggested. Operational processes refer to performing tasks related to a value chain's primary activities: inbound and outbound logistics (supplier and customer relations), production and operation, product and service development, and sales and marketing processes. On the other hand, management processes are not directly related to the operational (core or primary) processes. However, they assist in carrying out the support functions of a business. Management processes are associated with administration, allocation, and utilization of resources, communication, coordination, and control conducted at different organizational levels. They can help improve decision-making related to resource allocation and utilization, strategic planning, new product planning, new market entry planning, and budgetary control. To assess the management process capabilities, different measures are adopted, including decision-making performance (e.g., Aydiner et al., 2019; Mishra et al., 2018; Yichuan Wang \& Byrd, 2017), knowledge management processes (e.g., Jalilvand et al., 2019; Pérez-López \& Alegre, 2012), strategic planning capability and strategic orientation (e.g., Aydiner et al., 2019; Yeh et al., 2012), organizational learning (e.g., Radhakrishnan et al., 2008), and absorptive capacity (e.g., O.-K. (Daniel) Lee et al., 2015; Yichuan Wang \& Byrd, 2017). 
On the other hand, operational process capabilities is assessed using measures in supplier relations (e.g., Byrd et al., 2008; Byrd \& Davidson, 2003), production and operations (e.g., Dehning et al., 2007; Shahzad et al., 2020), product and service enhancement (e.g., Lyver \& Lu, 2018; Razalli et al., 2017; Soto-Acosta et al., 2018), sales and marketing (e.g., Srimarut \& Mekhum, 2020), and customer relations (e.g., Fernández-Mesa et al., 2014; Mithas et al., 2011).

\section{IS Measures Consequence: Firm Performance}

One of the most important topics in the ISBV research domain is the question of what to measure. During the past three decades, the body of ISBV literature has grown enormously, and so has the number of firm performance measures investigated. Two broad categories of accounting and marketbased firm performance measures are intensively discussed in the literature. Accounting measures are used to assess firm performance, such as income growth, sales growth, and profitability ratios, return on assets (ROA), return on equity (ROE), return on sales (ROS), and return on investment (ROI). ROA focuses on the firm's overall performance and is measured as operating income or net income divided by total assets (e.g., Chae et al., 2018; Otim et al., 2012; L.J. Yao et al., 2009). ROE compares the profits generated by the stockholders' investment and is measured as net income divided by the owners' total investment (stockholders' equity) (e.g., Ong \& Chen, 2016; L.J. Yao et al., 2009). ROS represents a firm's ability to generate income from sales revenue and is measured as net income divided by total sales revenue (e.g., Chae et al., 2018; Mahmood \& Mann, 1993b; L.J. Yao et al., 2009). ROI is measured as the amount of return on a particular investment, relative to the investment's cost (e.g., Badri \& Alshare, 2008; Chakravarty et al., 2013; Y. Chen et al., 2014; Mahmood \& Mann, 1993b; L.J. Yao et al., 2009).

Other accounting-based performance measures, such as inventory turnover (Mukhopadhyay et al., 1995; Zhu, 2004), gross or operating margins (S. Bharadwaj et al., 2007; Shin, 2006; Zhu, 2004), cash flow (Badri \& Alshare, 2008; Thakurta \& Guha Deb, 2018), market share (Aydiner et al., 2019; Barua et al., 1995; Radhakrishnan et al., 2008), and sales growth (Y. Chen et al., 2014; Ravichandran et al., 2005) are also adopted in the reviewed literature. Some research tried to adopt productivity measures such as operating income to employees (A.S. Bharadwaj, 2000; Chae et al., 2018), sales to employee (Mahmood \& Mann, 1993a; Marshall \& Byrd, 1997), and revenue to employee (Anthony Byrd et al., 2006; Vinekar \& Teng, 2012; Zhu \& Kraemer, 2002).

Similar to the results of Dehning and Richardson (2002), we observed that ROA and ROS are still among the most widely adopted measures of firm performance. However, accounting-based performance measures encounter severe challenges in dealing with the effect of underlying macro and industry factors, timing issues, and eliminating alternative explanations (Masli et al., 2011). As accounting-based performance measures are backward-looking, they merely reflect past performance. Accordingly, researchers must consider a time lag between IS measures (more specifically, IS investment) and value creation at the firm level. Besides, researchers must rule out alternative explanations and spurious correlations. Substantial research shows a strong serial correlation in accounting measures, which researchers must consider when measuring current or future performance (Dehning et al., 2007). An alternative approach to control for spurious correlations is to control for past or current performance when examining future performance (e.g., Campbell, 2012; Dale Stoel \& Muhanna, 2009; Henderson et al., 2010; Ho et al., 2011).

Some other research also employs market-based performance measures. Market-based performance measures are forward-looking and, thus, reflect expected ROI. Market measures include the market value of common equity (Henderson et al., 2010), total market capitalization (Dehning et al., 2006), or Tobin's q (Havakhor et al., 2019; R. Sabherwal et al., 2019; Steelman et al., 2019) that estimates the effectiveness of the firm in foreseeing and rapidly adapting to its changing environment. These market measures reflect the expected IS influence on long-term performance. Other measures are adopted in both long-term and short-term market reactions to IT investment announcements. For the long-term firm performance assessment using these set of measures, which is within the scope of 
this research, we can refer to long term abnormal returns (e.g., Li \& Huang, 2012) and buy-and-hold return (BAHR) (e.g., Henderson et al., 2010; Thakurta \& Guha Deb, 2018).

There are also some hybrid measures to estimate firm performance. For instance, Radhakrishnan et al. (2008) used Altman Z-score, an output of a credit-strength test that gauges a publicly-traded company's likelihood of bankruptcy. Altman Z-score uses profitability, leverage, liquidity, solvency, and activity ratios, which are both accounting-based and market-based ratios. Another set of hybrid performance measures are those that are mainly subjective such as competitive advantage (e.g., Bhatt et al., 2010; Bhatt \& Grover, 2005; Gu \& Jung, 2013) and customer satisfaction (e.g., Liu et al., 2013; Mithas et al., 2016). Data to estimate such measures are generally collected through primary sources such as surveys. Some research defines firm performance as a latent variable incorporating a mix of accounting-based, market-based, and other subjective measures as the measurement items (e.g., Aydiner et al., 2019; Mithas et al., 2016; Ong \& Chen, 2016).

Finally, there are some industry-specific performance measures. For instance, patient revenue per day (e.g., Devaraj \& Kohli, 2000, 2003), patient revenue per admission (e.g., Devaraj \& Kohli, 2000), revenue per bed (e.g., Baker et al., 2008), mortality rates (e.g., Devaraj \& Kohli, 2000, 2003), and adjusted patient days (e.g., Ko \& Osei-Bryson, 2004; Menon et al., 2009) are among the healthcare industry-specific performance measures. Competitive performance as room occupancy and new customers attracted (Cohen \& Olsen, 2013) in the hospitality industry, payroll expense, market share of deposits, and market share of loans (Kim \& Davidson, 2004) banking industry are other industryspecific measures. To sum up, based on the data provided in Appendix II, 58.9\% of research have adopted objective measures, $39.4 \%$ used subjective measures, and $1.6 \%$ employed hybrid measures to assess firm performance. Even though Chau et al. (2007), based on a review (41 papers from PACIS during 1993-2005, and 49 papers from ECIS during 2000-2005), suggested that there is a general shift from using objective measures to perceptual (subjective) measures, our observations suggest it differently. While we observe an increasing number of research using subjective datasets over the period, objective measures have been dominated until 2012, and the trend has just reversed after 2012.

\section{Conceptualization of ISBV Model}

This section explores different types of relations investigated in the ISBV research. Specifically, this section addresses RQs 2-5. Even though it is well established in the literature that IS measures do not directly affect firm performance, $75.7 \%$ of reviewed papers $(n=178)$ investigated IS measures' direct effect on firm performance, without any mediated effect (path 4 in Figure 2). $28.5 \%(n=67)$ of studies investigated paths 2 and $14.0 \%(n=33)$ examined path 3. Path 1 , with $6.8 \%(n=16)$ of studies, accounts for the least explored link. Contextual factors and time lag effect were examined in $60 \%(n=141)$ and $20 \%(n=47)$ of the literature, respectively. As more than a single path could be examined within a single research, the sum of the percentages is above one.

We summarize the findings on the coded relationships in Tables 2-5. In these tables, columns refer to the type of relationships that can be positive, negative, mixed, and non-significant. We code those types of relations as mixed, where the significance or the direction (positive or negative) of the relationship is different, for instance, under different moderating variables, throughout the lagged time period, or for a different set of measurement items. More specifically, regarding the latter case, if in one research, the effect of IS investment on ROA is positive, while it is not significant for ROE, as another firm performance measure, we code this as mixed. Regardless of the direction of the proposed relations, they are labeled as non.sig if they are not significant.

\section{IS Measures Determinants and IS Measures (Path 1)}

Only 16 studies (6.8\%) in our sample investigated IS measures determinants. However, the sample contains only studies that examined path 1 along with any other paths simultaneously. This approach will help to have a broader view of the whole process. Accordingly, we excluded studies that merely incorporated path 1 . We have not found any research that focuses on IS use determinants in the sample 
of ISBV literature. Also, we have found that technological determinants were not investigated in our reviewed ISBV literature. However, we have found determinants for IS investment and IS capabilities in the organizational and environmental category with primarily positive impact.

Table 2 shows that prior firm performance is the most used determinants of IS measures. Weill (1992), for the first time, suggested a relationship between IS investment and prior firm performance. Later, Hu and Plant (2001), using causality models and three samples of firm-level financial data, failed to confirm that IT investments cause the improvement of firms' financial performance. On the contrary, the causal models suggest that improved financial performance over consecutive years may have contributed to increased IT investment in the subsequent year. In line, Salge et al. (2015) proposed a negative relationship between hospitals' prior performance and their subsequent IS investment level. However, using longitudinal data of 153 hospitals over the years of 2002-2007, they failed to confirm their hypothesized relation.

The competitive environment also positively impacts IS investments (Purnama \& Subroto, 2016; Sriram \& Stump, 2004). The prior studies investigated competition at a general market level: competitive climate (Sriram \& Stump, 2004); industry concentration (Kobelsky et al., 2008); and competitive intensity (Purnama \& Subroto, 2016). The prior studies also investigated competition at the IS level: industry strategic IS role (Kobelsky et al., 2008) and competitors' IS intensity (Ravichandran et al., 2009). The impact of competition can be explained by the mimetic search concept used by Salge et al. (2015).

\section{IS Measures and Process Performance Relationships (Path 2)}

The relationship between IS measures and process performance has been investigated 87 times (in 67 papers). The effect of IS capabilities on process capabilities has been of the most significant research interest, followed by IS use and IS investment (see Table 3). We further analyze the effects of IS measures at two operational and management process capabilities levels. According to the results, scholars were more interested in the effects of IS measures on operational process capabilities than management process capabilities.

Substantial research has proposed a positive relationship between IS measures and process performance. Interestingly, we did not observe any significant negative relationship regarding the link. However, two research propose a "no-effect" relationship. Ray et al. (2005) propose that generic IS, the level of IT spending, and technical IT skills, per se, do not explain variance in the performance of the customer service process. Later, Jeffers et al. (2008) re-examine the proposition of Ray et al. (2005) on the link between generic IS use and process performance. They argue that there are complementarities between shared business-IS knowledge and business work practice and between the scope of IS applications and open communication culture in affecting the customerservice process performance.

There have also been some mixed results in some of the prior research. One reason for such mixed results is the different operationalization of IS measures. For instance, some research view IS capabilities as an umbrella term to refer to a bunch of capabilities and investigate the effects of each capability on process performance. Therefore, the aggregated result is mixed as some relations might be positively significant, and others not. For instance, Mao et al. (2020) view IS capabilities as IS knowledge, IS operations, and IS objects (assets). While the first two items positively influence absorptive capacity, 'IS assets' do not depict such an effect. Accordingly, it is coded as mixed. The same is the case for Aydiner et al. (2019), where they operationalized IS capabilities as infrastructure capability, human resource capability, and administrative capability. Again, not all items carry the same effect type. Besides, different levels of IS investment or use might have different impacts on business processes. For instance, business analytics might impact firm agility (Ashrafi et al., 2019), while using CAD/CAM systems can yield better product cycle time and defect rate (Macher \& Mowery, 2009). Therefore, the relationship can be mixed when authors have many IS with different functions that could affect process performance differently. In a similar vein, the variation of operationalization in 
Table 2. IS measures determinants based on the TOE framework

\begin{tabular}{|l|c|c|c|c|c|}
\hline \multicolumn{1}{|c|}{ Title } & Positive & Negative & Mixed & Non.sig & Sum* \\
\hline O01. Prior firm performance & 3 & 0 & 0 & 1 & 4 \\
\hline O02. Financial slack & 1 & 0 & 1 & 0 & 2 \\
\hline O03. Entrepreneurial orientation & 2 & 0 & 0 & 0 & 2 \\
\hline O04. Technology orientation & 2 & 0 & 0 & 0 & 2 \\
\hline O05. Marketing orientation & 1 & 0 & 1 & 0 & 2 \\
\hline O06. Organizational learning orientation & 2 & 0 & 0 & 0 & 2 \\
\hline O07. Proportion of institutional ownership & 0 & 0 & 1 & 0 & 1 \\
\hline O08. Quality orientation & 1 & 0 & 0 & 0 & 1 \\
\hline O09. Industry type: high/low tech & 1 & 0 & 0 & 0 & 1 \\
\hline O10. Diversification & 1 & 0 & 0 & 0 & 1 \\
\hline O11. Debt ratio & 0 & 1 & 0 & 0 & 1 \\
\hline O12. Growth & 0 & 1 & 0 & 0 & 1 \\
\hline O13. Innovativeness & 1 & 0 & 0 & 0 & 1 \\
\hline O14. Supply chain efforts & 1 & 0 & 0 & 0 & 1 \\
\hline O15. IS intensity & 1 & 0 & 0 & 0 & 1 \\
\hline O15. Supply chain performance & 1 & 0 & 0 & 0 & 1 \\
\hline O16. Information intensity & 1 & 0 & 0 & 0 & 1 \\
\hline E01. Environmental uncertainty & 3 & 0 & 0 & 0 & 3 \\
\hline E02. Competitors' IS intensity & 2 & 0 & 0 & 0 & 2 \\
\hline E03. Competitive environment & 2 & 0 & 0 & 0 & 2 \\
\hline E04. Customers' IS intensity & 1 & 0 & 0 & 0 & 1 \\
\hline E05. Suppliers' IS intensity & 1 & 0 & 0 & 0 & 1 \\
\hline E06. Regulative legitimacy & 1 & 0 & 0 & 0 & 1 \\
\hline E07. Industry concentration & 1 & 0 & 0 & 0 & 1 \\
\hline
\end{tabular}

the process performance measures is another source for mixed results. As introduced before, there are two broad categories of management and operational process capabilities, with different underlying measurement items.

This path has observed more research interest from 2006, probably inspired by some research such as Dehning and Richardson (2002), Dedrick et al. (2003), and Melville et al. (2004), who highlighted the role of intermediate processes in the relationship between IS measures and business value.

\section{Process Performance and Firm Performance Relationships (Path 3)}

The effect of process performance on firm performance was addressed by 33 published papers. Operational process performance on the independent variable and hybrid performance on the dependent variable side is the more explored areas (see Table 4). More interestingly, we did not observe any research investigating the effect of process performance on market performance measures. Besides, there has been no negatively articulated hypothesis for these links.

Most of the relations from process performance measures to accounting performance measures are positive and significant, with two exceptions. Grimmer et al. (2018) observed that a prospector and a defender/analyzer strategic orientation predicted small retail firm performance, while such an effect was not significant for the reactor orientation. Therefore, the results were mixed, based on the adopted strategic orientation of a firm. Pérez-López and Alegre (2012) also failed to support a positive relationship between knowledge management processes and accounting performance measures of ROA, ROI, and profitability. For the link from process performance to hybrid firm performance, positive relations outweigh, excluding some refuted hypotheses between decision-making performance and hybrid performance (e.g., ROI, ROS, cost reduction, inventory reduction, and customer loyalty) 
Table 3. The effect of IS measures on process capabilities

\begin{tabular}{|c|c|c|c|c|c|}
\hline Relationship & Positive & Negative & Mixed & $\begin{array}{c}\text { Non. } \\
\text { sig }\end{array}$ & Sum \\
\hline IS investment $\rightarrow$ Process capabilities & 2 & $\mathbf{0}$ & 2 & 3 & 7 \\
\hline IS investment $\rightarrow$ Operational process capabilities & 2 & 0 & 2 & 3 & 7 \\
\hline IS investment $\rightarrow$ Management process capabilities & 0 & 0 & 0 & 0 & 0 \\
\hline IS capabilities $\rightarrow$ Process capabilities & 53 & $\mathbf{0}$ & 7 & 6 & $\underline{66 *}$ \\
\hline IS capabilities $\rightarrow$ Operational process capabilities & 35 & 0 & 6 & 2 & $\underline{43 *}$ \\
\hline IS capabilities $\rightarrow$ Management process capabilities & 18 & 0 & 1 & 4 & $\underline{23 *}$ \\
\hline IS use $\rightarrow$ Process capabilities & 8 & 0 & 4 & 2 & 14 \\
\hline IS use $\rightarrow$ Operational process capabilities & 7 & 0 & 2 & 1 & $\underline{10^{*}}$ \\
\hline IS use $\rightarrow$ Management process capabilities & 1 & 0 & 2 & 1 & 4 \\
\hline IS measures $\rightarrow$ Process capabilities (Total) & 63 & $\mathbf{0}$ & 13 & 11 & $\underline{87 *}$ \\
\hline
\end{tabular}

* In the sum column, the underlined numbers refer to factors that have been empirically examined at least five times; numbers marked with asteroid denotes at least $60 \%$ of consistency for positive relations.

(Aydiner et al., 2019) or between employee outcomes and hybrid performance (e.g., competitive performance, new customers attracted, profitability, and sales) (Cohen \& Olsen, 2013).

\section{IS Measures And Firm Performance Relationships (Path 4)}

Researchers have shown great interest in analyzing the extent to which IS measures influence firm performance. All 178 ISBV papers that examined path 4 have proposed a positive relationship between IS measures and firm performance (see Table 5). The only exception is Thakurta and Guha Deb's (2018) longitudinal research on Indian firms' data from 2000 to 2014, considering 1-5 years of timelag. They confirmed a negative impact of IS investment on firm performance manifested through a decline in both operating and equity market performance. Almost half of all --relationships between IS measures and firm performance are positive and significant. Nearly two-sixth of the relationships are mixed, and one-sixth of them are non-significant.

We coded 115 relationships from IS measures to accounting performance measures. ROA and ROS are the most widely adopted measures of accounting performance. Nearly half of those links are statistically positive and significant. The impact of IS measures on market performance measures is the least explored area. Indeed, most of the research addressing this relation uses event studies and investigates the immediate effect introduced in Figure 1, which is out of our research scope. Tobin q is the most used market performance measure (e.g., Havakhor et al., 2019; Sabherwal et al., 2019; Steelman et al., 2019). Over 65 percent of the paths confirm a positive and significant relation between IS measures and market performance measures.

\section{ISBV and Contextual Factors (Path 5)}

One of the main difficulties in identifying ISBV has been the isolation of IS effects from other factors that may also contribute to firm performance (Kohli \& Grover, 2008). Hence, the question is "under what conditions does IT pay off?" not "does IT pay off?" (Schryen, 2013). ISBV research adopted a broad set of contextual factors as control and moderating variables to deal with that sort of effect. We categorize these factors into IS, firm, industry, and country-level variables. The least explored category of control and moderating effects is the IS-level factors. IS age (Dehning et al., 2007; Ordanini \& Rubera, 2010), IS type and IS strategic role type such as automate, informate, and transform (S. Aral \& Weill, 2007; Hendricks et al., 2007; Otim et al., 2012; Walsh et al., 2010), IS 
Table 4. The effect of process capabilities on form performance

\begin{tabular}{|c|c|c|c|c|c|}
\hline Relationship & Positive & Negative & Mixed & Non.sig & Sum* \\
\hline Operational process capabilities $\rightarrow$ Firm performance & 25 & $\mathbf{0}$ & 1 & $\mathbf{0}$ & $\underline{26 *}$ \\
\hline Operational process capabilities $\rightarrow$ Accounting performance & 7 & 0 & 0 & 0 & $\underline{7 *}$ \\
\hline Operational process capabilities $\rightarrow$ Market performance & 0 & 0 & 0 & 0 & 0 \\
\hline Operational process capabilities $\rightarrow$ Hybrid performance & 18 & 0 & 1 & 0 & $\underline{19 *}$ \\
\hline Management process capabilities $\rightarrow$ Firm performance & 9 & $\mathbf{0}$ & 1 & 4 & $\underline{14 *}$ \\
\hline Management process capabilities $\rightarrow$ Accounting performance & 2 & 0 & 1 & 1 & 4 \\
\hline Management process capabilities $\rightarrow$ Market performance & 0 & 0 & 0 & 0 & 0 \\
\hline Management process capabilities $\rightarrow$ Hybrid performance & 7 & 0 & 0 & 3 & $\underline{10 *}$ \\
\hline Process capabilities $\rightarrow$ Firm performance (total) & 34 & $\mathbf{0}$ & 2 & 4 & $\underline{40 *}$ \\
\hline
\end{tabular}

* In the sum column, the underlined numbers refer to factors that have been empirically examined at least five times; numbers marked with asteroid denotes at least $60 \%$ of consistency for positive relations.

Table 5. The effect of IS measures on firm performance

\begin{tabular}{|l|c|c|c|c|c|}
\hline \multicolumn{1}{|c|}{ Relationship } & Positive & Negative & Mixed & Non.sig & Sum* \\
\hline IS investment $\rightarrow$ Firm performance & $\mathbf{4 6}$ & $\mathbf{2}$ & $\mathbf{4 2}$ & $\mathbf{1 3}$ & $\underline{\mathbf{1 0 3}}$ \\
\hline IS investment $\rightarrow$ Accounting performance & 33 & 1 & 25 & 9 & $\underline{68}$ \\
\hline IS investment $\rightarrow$ Market performance & 8 & 1 & 2 & 1 & $\underline{12}$ \\
\hline IS investment $\rightarrow$ Hybrid performance & 5 & 0 & 15 & 3 & $\underline{23}$ \\
\hline IS capabilities $\rightarrow$ Firm performance & $\mathbf{3 3}$ & $\mathbf{0}$ & $\mathbf{1 8}$ & $\mathbf{1 4}$ & $\underline{\mathbf{6 5}}$ \\
\hline IS capabilities $\rightarrow$ Accounting performance & 15 & 0 & 11 & 6 & $\underline{32}$ \\
\hline IS capabilities $\rightarrow$ Market performance & 1 & 0 & 1 & 0 & 2 \\
\hline IS capabilities $\rightarrow$ Hybrid performance & 17 & 0 & 6 & 8 & $\underline{31}$ \\
\hline IS use $\rightarrow$ Firm performance & $\mathbf{1 5}$ & $\mathbf{0}$ & $\mathbf{5}$ & $\mathbf{5}$ & $\underline{\mathbf{2 5}}$ \\
\hline IS use $\rightarrow$ Accounting performance & 9 & 0 & 4 & 2 & $\underline{15}$ \\
\hline IS use $\rightarrow$ Market performance & 0 & 0 & 0 & 2 & 2 \\
\hline IS use $\rightarrow$ Hybrid performance & 6 & 0 & 1 & 1 & $\underline{2}$ \\
\hline IS measures $\rightarrow$ Firm performance (total) & $\mathbf{9 4}$ & $\mathbf{2}$ & $\mathbf{8 5}$ & $\mathbf{3 2}$ & $\underline{\mathbf{2 1 3}}$ \\
\hline
\end{tabular}

* In the sum column, the underlined numbers refer to factors that have been empirically examined at least five times; numbers marked with asteroid denotes at least $60 \%$ of consistency for positive relations.

objective (IS focus on business improvements) (Gu \& Jung, 2013), and IS service quality (Nakata et al., 2008) are the only factors we observed within the IS-level contextual factors.

As for the firm level factors, (a) IS measures such as IS investment (e.g., Liu et al., 2018; Lu \& Ramamurthy, 2011), and IS capabilities (e.g., Aral \& Weill, 2007; Wang et al., 2015); (b) firm demographics such as firm size (e.g., Chae et al., 2018; Havakhor et al., 2019; Steelman et al., 2019; T. Wang et al., 2018), firm age (e.g., Chakravarty et al., 2013; Ho et al., 2011; Sabherwal et al., 2019), IS department size (e.g., Liu et al., 2013; Lu \& Ramamurthy, 2011; Mao et al., 2020), and IS department age (e.g., Lu \& Ramamurthy, 2011; Mao et al., 2020); (c) data on expenditures such as R\&D intensity (e.g., Chari et al., 2008; Havakhor et al., 2019; Lee, 2008; Otim et al., 2012), and advertising intensity (e.g., Chari et al., 2008; Dewan \& Ren, 2011; Havakhor et al., 2019; Henderson et 
al., 2010); (d) financial indices such as ROA (e.g., Ravichandran et al., 2009), ROE (e.g., Brynjolfsson \& Hitt, 1996), and leverage or debt to equity ratio (e.g., Henderson et al., 2010; Otim et al., 2012; Xue et al., 2012); and finally (e) performance related indices such as prior performance (e.g., Campbell, 2012; Ho et al., 2011; Tanriverdi, 2006), and relative performance (e.g., Trainor et al., 2011) are intensively adopted in the literature.

At the industry level, the industry sector is widely adopted as a control variable (e.g., Aydiner et al., 2019; Mao et al., 2020; Xue et al., 2012). Industry IS intensity (Gu \& Jung, 2013; Mao et al., 2020), environmental dynamism (e.g., Chakravarty et al., 2013; Xue et al., 2012), and regulation (e.g., Cepeda \& Arias-Pérez, 2019; Dewan \& Ren, 2011) are other frequent industry level control or moderating variables adopted in ISBV literature.

The country-level contextual factors are the least explored area, according to our review results. Location (Beccalli, 2007; Chowdhury, 2006; Zhang et al., 2013), prime rate change, and Gross National Product (GNP) change (Barua et al., 1995) are the only explored variables. However, taking the industry and country-level variables into account, the body of literature is still too small to draw a clear picture.

\section{The Effect Of Time Lag (Path 6)}

IS measures do not make immediate impacts on firm performance. There is usually a time lag between IS measures (e.g., IS investment, IS use) and ISBV realization at the firm level. The lag effect arises in organizations because of "technology assimilation and interaction" between the IT and organizational processes, which takes time to affect financial indicators (Radhakrishnan et al., 2008).

The ignored effect of time lag might be a source of the mixed and conflicting results in the relationships depicted in Figure 2. It takes time for IS to affect firm processes and operations. Despite the important role of time lag, it is not well addressed in the relationship between IS measures and process or firm performance. According to our review, only $20 \%$ of all papers $(n=47)$ investigated the time lag effect. Among these, one year is the most favored time lag period accounting for $6.4 \%$ of all reviewed papers (e.g., Dewan \& Ren, 2011; Mithas et al., 2016; Sabherwal et al., 2019) followed by two years (e.g., Dale Stoel \& Muhanna, 2009; Dehning et al., 2007). Some authors investigated longer time lag periods up to seven (Menon et al., 2009) or nine years (Stratopoulos \& Dehning, 2000).

Among the very scarce literature addressing the time-lag effect, Radhakrishnan et al. (2008) observe that the IT focal firms' operational process capabilities are significantly higher than the industry for all the five investigated years average. Kleis et al. (2012) propose a positive relationship between IS investment and the number of patents, taking two years of time lag into account. However, Dehning et al. (2007) observed mixed relationships between SCM implementation announcements and inbound, operations, outbound, and support process capabilities during a two-year period. When the effect of time lag was taken into account, we observe more mixed relationships as the effect could be positive for one year and non-significant for later years.

\section{Theoretical Approaches Used In ISBV Research}

Theories specify the research models, including the fundamental viewpoint, assumptions, constructs, and hypotheses. For example, the Resource-Based View (RBV) theory considers IS as a business resource. Firms may choose to invest in IS resources that are rare, inimitable, and non-substitutable (Bharadwaj, 2000). Dynamic Capability view as an extension of RBV refers to "the ability to integrate, build, and reconðgure internal and external competencies to address rapidly-changing environments" (Teece et al., 1997, p. 517).

Due to the complex nature of ISBV phenomena, researchers have employed several theoretical paradigms in examining ISBV. The aforementioned RBV (e.g., Aydiner et al., 2019; Bharadwaj, 2000; Zhang et al., 2013) and DC (e.g., Ashrafi et al., 2019; Mao et al., 2020; Pérez-López \& Alegre, 2012) are the most adopted views in ISBV research. 
Melville et al. (2004) suggest that IS can create business value. However, the extent and dimensions depend on external and internal factors. Contingency theory addresses this issue and speculates that alignment between relevant contextual, structural, and strategic factors creates ISBV. Using contingency theory, previous research posits that technological, organizational, and environmental factors help determine the combination of organizational structure and processes that yield superior performance (Lee et al., 2010). Firm size and industry sector are the most studied contextual factors under the view of contingency theory (e.g., Dixit \& Panigrahi, 2014; Hyvönen, 2007; Lee, 2008; Lee et al., 2010).

As another widely-used view, the theory of production tries to signify the relationship between the firm's inputs and outputs for a given state of the technology. Researchers use production functions such as Cobb-Douglas to model such relationships. For instance, a positive relationship between IS use and some accounting-based performance measures is suggested using Cobb-Douglas production function in prior research (e.g., Kwon \& Stoneman, 1995; Mcguckin et al., 1998).

A summary of the list and frequency of adopted theories is presented in Table 6. According to the results, and despite the value of specifying the underlying view or theory of proposed models in ISBV research, nearly half of the reviewed literature does not refer to any specific theoretical view. This finding is in line with the "No theory on IS business value exists." argument of Schryen (2013, p. 150).

\section{DISCUSSIONS AND FUTURE RESEARCH SUGGESTIONS}

We confined the scope of our proposed research directions based on our review results to ground the suggestions in available data. In the following subsections, we have summarized these ISBV research potentials for each of the paths of Figure 2.

\section{The Role of IS Measures Determinants (Path 1)}

We observed the IS measures determinants (path 1) to be the least explored area in ISBV literature. We mapped different determinants on TOE dimensions. It revealed that 'IS use' determinants and technological determinants (as independent variables with an effect on IS measures) are not investigated in any of our reviewed literature, which could be considered a future research potential.

Investigating the effect of firm performance on subsequent IS investment is one of the interesting future research avenues. Most studies viewed IS investments as 'given,' unitary and unchanging, with the primary focus devoted to evaluating ISBV after the investments have been made (Baker et al., 2017; Polykarpou et al., 2018), which can be labeled as a unidirectional view of ISBV. However, without knowing how (positive/negative) performance influences subsequent IS investment, the ISBV theory cannot be complete. One of the first studies that tried to close this loop was conducted by Aral et al. (2006). They examined how improved firm performance, as a result of ERP systems usage, would enable the subsequent investment in SCM and CRM systems, which further improve performance. Their findings suggested that improved performance from ERP systems stimulates follow-on investments in SCM and CRM systems. Later, the research conducted by Salge et al. (2015) has widened the spectrum of IS investment research by including the initial allocation stage of IS investments, during which decision-makers decide how an organization's scarce financial resources should be spent on IS. Lately, Baker et al. (2017), in the healthcare sector, discovered a positive causal relationship claiming that an increase in productivity in a given period leads to an increase in IS investment in the next period. They suggested that future work could focus on different industries or different national and cultural contexts. In line with their proposed research stream, we suggest exploring the closed performance-IS investment loop using performance feedback theory. 
Table 7. Theoretical views adopted in prior ISBV research

\begin{tabular}{|l|l|l|l|}
\hline \multicolumn{1}{|c|}{ Theory } & $\#$ & \multicolumn{1}{c|}{ Theory } & $\#$ \\
\hline Resource-Based View (RBV) & 60 & Transaction Cost Theory (TCE) & 3 \\
\hline Dynamic Capabilities view (DC) & 19 & Agency theory & 2 \\
\hline Production theory & 18 & Fit perspective & 2 \\
\hline Contingency theory & 6 & Internalization theory & 2 \\
\hline Theory of competitive advantage & 5 & IS Success Model & 2 \\
\hline Institutional theory & 4 & Microeconomic theory & 2 \\
\hline Theory of complementarities & 6 & Organizational learning theory & 2 \\
\hline Resource advantage theory & 3 & Technology, Organization, Environment (TOE) & 2 \\
\hline System theory & 3 & No Theory & 113 \\
\hline
\end{tabular}

Note: Theories with a minimum of two frequencies are listed.

\section{The Relationship Between IS Measures and Process Performance (Path 2)}

According to our review, a vast majority of ISBV empirical research (70\%) investigated IS measures' direct effect on firm performance. This output-oriented approach allows us to answer what IS has induced, leaving how, why, and when concerns unanswered. Such an approach does not explain the divergence in ISBV, as it does not allow an analysis of how, why, and when IS creates business value. Answering these questions is crucial as firm performance could be simultaneously affected by dozens of other external and internal factors, making it remarkably challenging to isolate the influence of IS and to develop causal relationships. Researchers have tried to address this concern in two main ways. One stream of research introduces some mediators in the relationship between IS measure and firm performance. It can include only indirect effects (paths 2 and 3) or direct and indirect effects (path 4 in parallel with paths 2 and/or 3). The second stream conceptualizes and investigates the effects of different IS, firm, industry, and country-level factors as moderators or control variables. Regarding the first stream, early studies mostly focused on the direct relationships from IS measures to firm performance. However, inspired by some research such as Dehning and Richardson (2002), Dedrick et al. (2003), and Melville et al. (2004), who highlighted the role of intermediate processes in the relationship between IS measures and firm performance, we observed more interest into investigating indirect effects from 2006. According to our review analysis, the effects of IS measures on operational process capabilities have been of more research interest than the management process capabilities. More specifically, there is a dearth of studies investigating the effect of IS investment and IS use on management process capabilities, and the few conducted research show conflicting results. In line with Masli et al. (2011), we also suggest this research gap as a future research potential, especially using perspectives such as absorptive capacity, ambidexterity, and organizational learning.

Furthermore, our review revealed that there is no study investigating the interrelations among IS measures. There have been some efforts examining IS capabilities' moderating role on the link from IS investment to process performance (Wang et al., 2015) and firm performance (Aral \& Weill, 2007). However, our understanding of IS investment's impact on IS capabilities or the role of IS capabilities in IS use is limited, and future research could target this research direction.

\section{The Relationship Between Process Capabilities and Firm Performance (Path 3)}

One of the surprising results of the analysis on the relationship between process capabilities and firm performance was that there had been no study investigating process capabilities' effect on market performance measures. This is also almost the case for the direct effects of IS measures on market performance. This gap is crucial as the dominant accounting-based performance measures encounter 
severe challenges in dealing with the effect of underlying macro and industry factors, timing issues, and eliminating alternative explanations (Masli et al., 2011). They are also backward-looking compared to the forward-looking market performance measures that reflect expected business values. Therefore, we suggest focusing more on ISBV in terms of market performance in future research.

\section{The Relationships Between IS Measures and Firm Performance (Paths 4)}

Most empirical ISBV studies consider IS measures in an aggregated way, as discussed earlier. We found only a handful number of empirical studies that analyze the business value of specific IS types. Then, the question is whether this high-level approach is suitable to understand ISBV. In this line, Aral and Weill (2007, p. 763) argued that due to this issue, "we know little about the relative performance contributions of different types of IS investments and whether different IS investments impact different aspects of firm performance." Bharadwaj et al. (1999, p. 1020) concluded that "firms benefit unequally from their different IS investments." Schryen (2013) proposed that "empirical results of different studies are hard to compare (danger of comparing apples with pearsFor example, investments of equal amounts in the networking infrastructure and business analytics tools (enabling firms to discover the hidden market and customer patterns and incorporate that data-driven insight into the decision-making process), are likely to yield a different ISBV. In this line, Masli et al. (2011) recommend that researchers seek alternate measures of ISBV or firm performance that are closely related to the types of IS measures in question. They specifically suggested investigating the nonfinancial effects of CRM implementation in improved customer value. Emerging technologies have different ISBV. For instance, Social media can bring business values such as customer interaction (Senadheera et al., 2011) and market analytics (Dellarocas et al., 2010). Cloud computing can facilitate partnering agility (Liu et al., 2016), and satisfaction, social value, and green IT (Chou, 2015), to name only a few. Business analytics can create value, for instance, in decision-making performance (Rouhani et al., 2016), innovation performance (Ashrafi \& Zare Ravasan, 2018), and firm agility (Ashrafi et al., 2019; Ghasemaghaei et al., 2017). As another cutting-edge technology, Blockchain has business values such as supply chain resilience (Min, 2019) and business model transformation (Morkunas et al., 2019). As can be observed from these few exemplar cases, there are diverse business values of different IS, which is unlikely to be the case in others. Besides, the use of these emerging technologies is relatively new to many firms, and they have limited knowledge on how to exploit the potentials of new IS. We advocate shifting from the general term of ISBV to domain specific business value, focusing on specific potentials of each technology. There are early attempts in this regards to formulate business value models for some of the emerging technologies such as for social media (Culnan et al., 2010) and business analytics (Trieu, 2017).

Most longitudinal research, especially those conducted based on the US firms' data, use old data because two primary data providers (IDG and IW500) have stopped offering their updated dataset to the market. As a result, even the most recent research (e.g., Sabherwal et al., 2019; Steelman et al., 2019) uses data for utmost up to 2008 that is a decade behind. That might affect the validity of the results and practice implications for current days because of the rapidly changing IS domain and different variables of interest in different IS eras. This argument is in line with the findings of Sabherwal and Jeyaraj (2015), suggesting that ISBV increases over time throughout IS eras (i.e., mainframe computing era, 1971-1982; personal computing era, 1983-1994; network computing era, 1995-2002; and mobile computing era, 2002-2013). Earlier, Brynjolfsson and Yang (1996) also suggested that ISBV is better observed for studies that used more recent datasets. Therefore, the question is whether insights of analyzed data of one era apply to the next era with different business and technological assumptions. Besides, we expect that ISBV research will continue to be limited by the lack of extensive sets of up-to-date panel data (Masli et al., 2011). This is perhaps why research increasingly uses cross-sectional firm-level surveys as their data sources, other than longitudinal datasets during the last few years. Accordingly, even though it does not make sense to suggest approaching surveys than longitudinal panel data in future research, due to the inherent limitations 
of perceptional surveys, we suggest scholars to justify how the insights obtained from old data can be still valid and applicable to current practices.

\section{The Role of Contextual Factors (Path 5)}

Regarding the second stream of research, as mentioned earlier and to address difficulties in isolating IS effects from other factors that may also contribute to firm performance (Kohli \& Grover, 2008), researchers examined different contextual factors that can be categorized as IS, firm, industry, and country-level variables. Firm and industry-level variables are intensively investigated in the literature. However, the role of IS and country-level variables call for more empirical examinations. Because of the nature of different IS (e.g., infrastructure, transactional, informational, strategic) and the fact that different IS need different periods of learning and adjustment to create business value (Aral $\&$ Weill, 2007), we recommend future research to incorporate IS type and IS age in parallel in the empirical analysis to have a better view of ISBV. Turning to the country-level contextual factors, there is very scarce ISBV literature in this regard. This shortcoming is also highlighted in the Melville et al. (2004) review.

Based on the review results, nearly $64 \%$ of the literature used US firms' data, and less than six percent conducted in a multi-country context. There are many research potentials in this context that can be addressed. One interesting country-level analysis that can be included in future firm-level ISBV research is discovering whether the developed and developing country context influences ISBV realization. Prior research has investigated that effect at the national level ISBV, but firm-level studies addressing this concern are scarce. The effect of county-level regulation intensity (differs from industry-level regulation intensity) can also be considered a potential moderator in the ISBV models, which is not addressed in prior ISBV studies. Regarding firm-level moderators, even though it is the most adopted category of contextual variables, we suggest examining the role of IS prior experience, strategy (e.g., innovator and defender), and IS governance in future ISBV models.

Furthermore, while there are many ways in which firms can gain a business value from IS, it would be beneficial to consider enablers, barriers, critical success factors, and critical failure factors of ISBV generation and potential consequences (Piccoli \& Ives, 2005; Rajiv Sabherwal \& Jeyaraj, 2015). There is a substantial body of knowledge in some IS domains, such as ERPs, in this regard. However, due to each technology's specific features and potentials (e.g., Blockchain, social media, and cloud computing), technology-specific models need to be established, tailored, and validated. Future research should also focus on more industry-specific IS tools and applications, rather than generalizing findings from aggregated IS measures to all industries. For instance, in the healthcare discipline, scholars can adopt medial IT capital and patient management systems (e.g., Ko \& OseiBryson, 2004; Menon et al., 2009)general IS investment metrics. Research in the manufacturing industry could focus more on operation management tools and applications such as MRPs, ERPS, and SCMs. Scholars interested in the ISBV in the construction industry could investigate the business value of emerging IS-enabled approaches and tools such as Integrated Project Delivery (IPD) and Building Information Modeling (BIM) and enablers and challenges in this regard.

Finally, studying IT leaders' best practices, which has been the dominant research thread, we need to investigate and learn from failure cases. For instance, Avison et al. (2006) reviewed three large Australian failed IS projects and observed that managerial IS unconsciousness and poor IS governance led to ISBV creation failure. These lessons learned prevents firms from repeating the same mistakes and allows them to take advantage of best practices.

\section{The Role of Time Lag (Path 6)}

Future research also needs to incorporate time lag in the analysis because only $20 \%$ of the reviewed literature has investigated the time lag effect. Sabherwal and Jeyaraj (2015), reviewing 265 empirical papers published in 1990-2013, found that ISBV increases over time with IS progress, highlighting the importance of time lag in ISBV research. We suggest at least one year lag as the gap between 
IS investment and ISBV as it is mostly suggested and employed period (e.g., Dewan \& Ren, 2011; Mithas et al., 2016; Sabherwal et al., 2019).

ISBV research employing surveys as their data collection approach needs to address this concern in their sample selection and ensure that their sample cases meet the time lag criterion. One way to approach this is followed in Bharadwaj et al. (2007). They surveyed manufacturing firms around their IS capabilities, manufacturing-marketing coordination, manufacturing-IS coordination, manufacturingsupply chain coordination, and just-in-time (JIT) functions. For the objective measures (i.e., inventory turns, operating margin, and on-time ratio), they used Compustat data with a one-year time lag. At the same time, for the independent variables, they relied on the cross-sectional survey data. This approach could be adopted in future research to use the advantages of surveys and panel data simultaneously. This proposal aligns with Chan's (2000) suggestion that motivates having more balanced perspectives of ISBV by covering hard/objective and soft/subjective measures.

\section{CONCLUSION}

ISBV research is defined as research that examines the direct or indirect impacts of one or more IS measures on the process or firm performance measure. With the increasing role of IS in the business context over the last 30 years, academic studies have sought to examine whether and how IS contributes to business value. We proposed a synthesized ISBV model (see Figure 2) to address the research questions and examine the relationships among the model's main constructs. This framework places IS measures in the center and discovers their determinants and consequences. The review of 235 published journal papers explored different approaches to conceptualize (RQs 2-4) and operationalize (RQ1) the ISBV models, and underlying theories (RQ5). Accordingly, this research shows which concepts and relations are over-researched, which relations showed consistent or inconsistent results, and which concepts and relations need further investigations.

Our study was limited in several ways. First, SLRs are always affected by an arbitrary decision about the depth of source search. The review sample can be always enlarged, however, without text mining, the number of papers that could be manually analyzed and coded, needs to be reasonably limited. We chose quite extensive search queries but were thorough with applying inclusion and exclusion criteria to include only relevant studies that will not skew the findings. Second, we could use a more thorough bibliometric approach to describe the sample. However, the size of the paper would enlarge too much. Nevertheless, future studies could overtake these limitations.

Although we have outlined the specific directions for further research in the discussion, we suggest some ideas that can be employed in future SLRs in the ISBV field. First, a thematic study of leading topics in IS research could be performed. An example of this approach is a study focusing only on the International Journal of Information Management (see Donthu et al., 2021). A broader study encompassing top journals in the field could reveal the structural and popularity changes in the research topics and could contextualize the position and future potential of ISBV in research. Second, we revealed the degree of consistency of prior results regarding the relationships between different constructs. While some relationships (path 3 with process capabilities to firm performance) were repeatedly proven as positive and significant, some (path 4 with IS measures to firm performance) were investigated with mixed results. We believe that this can open or renew some research directions, such as using qualitative methods more frequently to explain and describe the phenomena. Third, we also revealed that a minimum of studies reported negative relations. While this can mean the strength of the general ISBV model, it could also mean the existence of positive results bias. Therefore, more studies such as the one published by Avison et al. (2006) are needed to investigate the hidden side of ISBV creation.

ISBV researchers could use this study in several ways. First, the proposed research opportunities to address the research gaps can help them target their research and overcome the shortcomings of the current body of ISBV knowledge. Second, the overview of used variables and revealed relations 
between them can improve the design of conceptual models and operationalization of qualitative and quantitative empirical studies (see Appendix II). Third, our detailed analysis of relations (paths in our study) between ISBV model variables can incentivize qualitative researchers to conduct explanatory studies that could bring the long-wanted light on mechanisms by which the ISBV is created. Practitioners can benefit from our study in the following ways. First, they can increase their knowledge of ISBV creation as our review comprehensively describes all the phases and measures that were investigated in the past. Second, when managing benefits (see Ward \& Daniel, 2012) they can design better performance indicators to evaluate their IS investments.

\section{ACKNOWLEDGMENT}

We acknowledge the financial support of the Grant Agency of the Czech Republic, GAČR (grant no. GA20-12081S). 


\section{REFERENCES}

AL-Shboul, M. A. (2019). Towards better understanding of determinants logistical factors in SMEs for cloud ERP adoption in developing economies. Business Process Management Journal, 25(5), 887-907. doi:10.1108/ BPMJ-01-2018-0004

Andersen, T. J., \& Segars, A. H. (2001). The impact of IT on decision structure and firm performance: Evidence from the textile and apparel industry. Academic Press.

Anthony Byrd, T., Lewis, B. R., \& Bryan, R. W. (2006). The leveraging influence of strategic alignment on IT investment: An empirical examination. Information \& Management, 43(3), 308-321. doi:10.1016/j. im.2005.07.002

Aral, S., Brynjolfsson, E., \& Wu, D. J. (2006). Which Came First, IT or Productivity? The Virtuous Cycle of Investment and Use In Enterprise Systems. Twenty-Seventh International Conference on Information Systems, 1819-1840. doi:10.2139/ssrn.942291

Aral, S., \& Weill, P. (2007). IT assets, organizational capabilities, and firm performance: How resource allocations and organizational differences explain performance variation. Organization Science, 18(5), 763-780. doi:10.1287/orsc.1070.0306

Arora, B., \& Rahman, Z. (2017). Information technology capability as competitive advantage in emerging markets: Evidence from India. International Journal of Emerging Markets, 12(3), 447-463. doi:10.1108/ IJoEM-07-2015-0127

Ashrafi, A., \& Zare Ravasan, A. (2018). How market orientation contributes to innovation and market performance: The roles of business analytics and flexible IT infrastructure. Journal of Business and Industrial Marketing, 33(7), 970-983. doi:10.1108/JBIM-05-2017-0109

Ashrafi, A., Zare Ravasan, A., Trkman, P., \& Afshari, S. (2019). The role of business analytics capabilities in bolstering firms' agility and performance. International Journal of Information Management, 47, 1-15. doi:10.1016/j.ijinfomgt.2018.12.005

Avison, D., Gregor, S., \& Wilson, D. (2006). Managerial IT unconsciousness. Communications of the ACM, 49(7), 88-93. doi:10.1145/1139922.1139923

Aydiner, A. S., Tatoglu, E., Bayraktar, E., \& Zaim, S. (2019). Information system capabilities and firm performance: Opening the black box through decision-making performance and business-process performance. International Journal of Information Management, 47, 168-182. doi:10.1016/j.ijinfomgt.2018.12.015

Badri, M. A., \& Alshare, K. (2008). A path analytic model and measurement of the business value of e-government: An international perspective. International Journal of Information Management, 28(6), 524-535. doi:10.1016/j. ijinfomgt.2006.10.004

Baker, J., Song, J., Jones, D., \& Ford, E. W. (2008). Information Systems and Healthcare XXIX: Information Technology Investments and Returns - Uniqueness in the Healthcare Industry. Communications of the Association for Information Systems, 23. Advance online publication. doi:10.17705/1CAIS.02321

Baker, J., Song, J., \& Jones, D. R. (2017). Closing the loop: Empirical evidence for a positive feedback model of IT business value creation. The Journal of Strategic Information Systems, 26(2), 142-160. doi:10.1016/j. jsis.2016.12.001

Bano, M., \& Zowghi, D. (2014). A systematic review on the relationship between user involvement and system success. Information and Software Technology, 58, 148-169. doi:10.1016/j.infsof.2014.06.011

Barua, A., Kriebel, C. H., \& Mukhopadhyay, T. (1995). Information Technologies and Business Value: An Analytic and Empirical Investigation. Information Systems Research, 6(1), 3-23. doi:10.1287/isre.6.1.3

Beccalli, E. (2007). Does IT investment improve bank performance? Evidence from Europe. Journal of Banking \& Finance, 31(7), 2205-2230. doi:10.1016/j.jbankfin.2006.10.022

Benitez-Amado, J., Llorens-Montes, F. J., \& Nieves Perez-Arostegui, M. (2010). Information technology-enabled intrapreneurship culture and firm performance. Industrial Management \& Data Systems, 110(4), 550-566. doi: $10.1108 / 02635571011039025$ 
Bharadwaj, A. S. (2000). A resource-based perspective on information technology capability and firm performance: An empirical investigation. MIS Quarterly: Management Information Systems, 24(1), 169-193. doi: $10.2307 / 3250983$

Bharadwaj, A. S., Bharadwaj, S. G., \& Konsynski, B. R. (1999). Information technology effects on firm performance as measured by Tobin's q. Management Science, 45(7), 1008-1024. doi:10.1287/mnsc.45.7.1008

Bharadwaj, S., Bharadwaj, A., \& Bendoly, E. (2007). The Performance Effects of Complementarities Between Information Systems, Marketing, Manufacturing, and Supply Chain Processes. Information Systems Research, 18(4), 437-453. doi:10.1287/isre.1070.0148

Bhatt, G., Emdad, A., Roberts, N., \& Grover, V. (2010). Building and leveraging information in dynamic environments: The role of IT infrastructure flexibility as enabler of organizational responsiveness and competitive advantage. Information \& Management, 47(7-8), 341-349. doi:10.1016/j.im.2010.08.001

Bhatt, G. D., \& Grover, V. (2005). Types of information technology capabilities and their role in competitive advantage: An empirical study. Journal of Management Information Systems, 22(2), 253-277. doi:10.1080/07 421222.2005.11045844

Bloom, N., Sadun, R., \& Reenen, J. V. (2012). Americans Do IT Better: US Multinationals and the Productivity Miracle. The American Economic Review, 102(1), 167-201. doi:10.1257/aer.102.1.167

Brynjolfsson, E. (1993). The productivity paradox of information technology. Communications of the ACM, 36(12), 66-77. doi:10.1145/163298.163309

Brynjolfsson, E., \& Hitt, L. (1996). Paradox Lost? Firm-level Evidence on the Returns to Information Systems Spending. Management Science, 42(4), 541-558. doi:10.1287/mnsc.42.4.541

Brynjolfsson, E., \& Yang, S. (1996). Information Technology and Productivity: A Review of the Literature. In Advances in Computers (Vol. 43, pp. 179-214). Elsevier. doi:10.1016/S0065-2458(08)60644-0

Byrd, T. A., \& Davidson, N. W. (2003). Examining possible antecedents of IT impact on the supply chain and its effect on firm performance. Information \& Management, 41(2), 243-255. doi:10.1016/S0378-7206(03)00051-X

Byrd, T. A., Pitts, J. P., Adrian, A. M., \& Davidson, N. W. (2008). Examination of a path model relating information technology infrastructure with firm performance. Journal of Business Logistics, 29(2), 161-187. doi:10.1002/j.2158-1592.2008.tb00091.x

Campbell, M. (2012). What a Difference a Year Makes: Time Lag Effect of Information Technology Investment on Firm Performance. Journal of Organizational Computing and Electronic Commerce, 22(3), 237-255. doi: $10.1080 / 10919392.2012 .696944$

Carr, N. G. (2003). IT doesn’t matter. Harvard Business Review, 81(5), 41-49. PMID:12747161

Cepeda, J., \& Arias-Pérez, J. (2019). Information technology capabilities and organizational agility: The mediating effects of open innovation capabilities. Multinational Business Review, 27(2), 198-216. doi:10.1108/ MBR-11-2017-0088

Chae, H.-C., Koh, C. E., \& Park, K. O. (2018). Information technology capability and firm performance: Role of industry. Information \& Management, 55(5), 525-546. doi:10.1016/j.im.2017.10.001

Chakravarty, A., Grewal, R., \& Sambamurthy, V. (2013). Information technology competencies, organizational agility, and firm performance: Enabling and facilitating roles. Information Systems Research, 24(4), 976-997. doi:10.1287/isre.2013.0500

Chan, Y. E. (2000). IT Value: The great divide between qualitative and quantitative and individual and organizational measures. Journal of Management Information Systems, 16(4), 225-261. doi:10.1080/074212 22.2000.11518272

Chari, M. D. R., Devaraj, S., \& David, P. (2008). Research note-The impact of information technology investments and diversification strategies on firm performance. Management Science, 54(1), $224-234$. doi:10.1287/mnsc. 1070.0743 
Chatterjee, D., Pacini, C., \& Sambamurthy, V. (2002). The shareholder-wealth and trading-volume effects of information-technology infrastructure investments. Journal of Management Information Systems, 19(2), 7-42. doi:10.1080/07421222.2002.11045723

Chau, P. Y. K., Kuan, K. K. Y., \& Liang, T.-P. (2007). Research on IT value: What we have done in Asia and Europe. European Journal of Information Systems, 16(3), 196-201. doi:10.1057/palgrave.ejis.3000666

Chen, J.-L. (2012). The synergistic effects of IT-enabled resources on organizational capabilities and firm performance. Information \& Management, 49(3-4), 142-150. doi:10.1016/j.im.2012.01.005

Chen, Y., Wang, Y., Nevo, S., Benitez-Amado, J., \& Kou, G. (2015). IT capabilities and product innovation performance: The roles of corporate entrepreneurship and competitive intensity. Information \& Management, 52(6), 643-657. doi:10.1016/j.im.2015.05.003

Chen, Y., Wang, Y., Nevo, S., Jin, J., Wang, L., \& Chow, W. S. (2014). IT capability and organizational performance: The roles of business process agility and environmental factors. European Journal of Information Systems, 23(3), 326-342. doi:10.1057/ejis.2013.4

Chou, D. C. (2015). Cloud computing: A value creation model. Computer Standards \& Interfaces, 38, 72-77. doi:10.1016/j.csi.2014.10.001

Chowdhury, S. K. (2006). Investments in ICT-capital and economic performance of small and medium scale enterprises in East Africa. Journal of International Development, 18(4), 533-552. doi:10.1002/jid.1250

Cohen, J. F., \& Olsen, K. (2013). The impacts of complementary information technology resources on the service-profit chain and competitive performance of South African hospitality firms. International Journal of Hospitality Management, 34(1), 245-254. doi:10.1016/j.ijhm.2013.04.005

Culnan, M. J., McHugh, P. J., \& Zubillaga, J. I. (2010). How large US companies can use Twitter and other social media to gain business value. MIS Quarterly Executive, 9(4).

Dale Stoel, M., \& Muhanna, W. A. (2009). IT capabilities and firm performance: A contingency analysis of the role of industry and IT capability type. Information \& Management, 46(3), 181-189. doi:10.1016/j.im.2008.10.002

Dedrick, J., Gurbaxani, V., \& Kraemer, K. L. (2003). Information Technology and Economic Performance: A Critical Review of the Empirical Evidence. ACM Computing Surveys, 35(1), 28. doi:10.1145/641865.641866

Dedrick, J., Kraemer, K., \& Shih, E. (2013). Information technology and productivity in developed and developing countries. Journal of Management Information Systems, 30(1), 97-122. doi:10.2753/MIS0742-1222300103

Dehning, B., Pfeiffer, G. M., \& Richardson, V. J. (2006). Analysts' forecasts and investments in information technology. International Journal of Accounting Information Systems, 7(3), 238-250. doi:10.1016/j. accinf.2006.07.001

Dehning, B., \& Richardson, V. J. (2002). Returns on Investments in Information Technology: A Research Synthesis. Journal of Information Systems, 24.

Dehning, B., Richardson, V. J., \& Zmud, R. W. (2007). The financial performance effects of IT-based supply chain management systems in manufacturing firms. Journal of Operations Management, 25(4), 806-824. doi:10.1016/j.jom.2006.09.001

Dellarocas, C., Gao, G., \& Narayan, R. (2010). Are consumers more likely to contribute online reviews for hit or niche products? Journal of Management Information Systems, 27(2), 127-158. doi:10.2753/MIS0742-1222270204

Devaraj, S., \& Kohli, R. (2000). Information Technology Payoff in the Health-Care Industry: A Longitudinal Study. Journal of Management Information Systems, 16(4), 41-67. doi:10.1080/07421222.2000.11518265

Devaraj, S., \& Kohli, R. (2003). Performance Impacts of Information Technology: Is Actual Usage the Missing Link? Management Science, 49(3), 273-289. doi:10.1287/mnsc.49.3.273.12736

Dewan, S., \& Ren, F. (2011). Information Technology and Firm Boundaries: Impact on Firm Risk and Return Performance. Information Systems Research, 22(2), 369-388. doi:10.1287/isre.1090.0261 
Dixit, G., \& Panigrahi, P. (2014). Information technology impact and role of firm age and export activity: An emerging economy context. Journal of Global Information Technology Management, 17(3), 169-187. doi:10. 1080/1097198X.2014.951295

Donthu, N., Kumar, S., Pandey, N., \& Gupta, P. (2021). Forty years of the International Journal of Information Management: A bibliometric analysis. International Journal of Information Management, 57, 102307. doi:10.1016/j.ijinfomgt.2020.102307

Fernández-Mesa, A., Ferreras-Méndez, J. L., Alegre, J., \& Chiva, R. (2014). IT competency and the commercial success of innovation. Industrial Management \& Data Systems, 114(4), 550-567. doi:10.1108/IMDS-09-20130389

Ghasemaghaei, M., Hassanein, K., \& Turel, O. (2017). Increasing firm agility through the use of data analytics: The role of fit. Decision Support Systems, 101, 95-105. doi:10.1016/j.dss.2017.06.004

Grimmer, L., Grimmer, M., \& Mortimer, G. (2018). The more things change the more they stay the same: A replicated study of small retail firm resources. Journal of Retailing and Consumer Services, 44, 54-63. doi:10.1016/j.jretconser.2018.05.012

Grover, V., Teng, J., Segars, A. H., \& Fiedler, K. (1998). The infuence of information technology diffusion and business process change on perceived productivity: The IS executive's perspective. Academic Press.

Gu, J.-W., \& Jung, H.-W. (2013). The effects of IS resources, capabilities, and qualities on organizational performance: An integrated approach. Information \& Management, 50(2-3), 87-97. doi:10.1016/j.im.2013.02.001

Hanafizadeh, P., \& Zareravasan, A. (2020). A Systematic Literature Review on IT Outsourcing Decision and Future Research Directions. Journal of Global Information Management, 28(2), 160-201. doi:10.4018/ JGIM.2020040108

Hao, S., \& Song, M. (2016). Technology-driven strategy and firm performance: Are strategic capabilities missing links? Journal of Business Research, 69(2), 751-759. doi:10.1016/j.jbusres.2015.07.043

Havakhor, T., Sabherwal, R., Steelman, Z. R., \& Sabherwal, S. (2019). Relationships between information technology and other investments: A contingent interaction model. Information Systems Research, 30(1), 291-305. doi:10.1287/isre.2018.0803

Henderson, B. C., Kobelsky, K., Richardson, V. J., \& Smith, R. E. (2010). The Relevance of Information Technology Expenditures. Journal of Information Systems, 24(2), 39-77. doi:10.2308/jis.2010.24.2.39

Hendricks, K. B., Singhal, V. R., \& Stratman, J. K. (2007). The impact of enterprise systems on corporate performance: A study of ERP, SCM, and CRM system implementations. Journal of Operations Management, 25(1), 65-82. doi:10.1016/j.jom.2006.02.002

Hitt, L. M., \& Brynjolfsson, E. (1996). Productivity, Business Profitability, and Consumer Surplus: Three Different Measures of Information Technology Value. Management Information Systems Quarterly, $20(2), 121$. doi: $10.2307 / 249475$

Ho, J. L. Y., Wu, A., \& Xu, S. X. (2011). Corporate Governance and returns on information technology investment: Evidence from an emerging market. Strategic Management Journal, 32(6), 595-623. doi:10.1002/smj.886

$\mathrm{Hu}$, Q., \& Plant, R. (2001). An Empirical Study of the Casual Relationship Between IT Investment and Firm Performance. Information Resources Management Journal, 14(3), 15-26. doi:10.4018/irmj.2001070102

Hyvönen, J. (2007). Strategy, performance measurement techniques and information technology of the firm and their links to organizational performance. Management Accounting Research, 18(3), 343-366. doi:10.1016/j. mar.2007.02.001

Irfan, M., \& Wang, M. (2019). Data-driven capabilities, supply chain integration and competitive performance: Evidence from the food and beverages industry in Pakistan. British Food Journal, 121(11), 2708-2729. doi:10.1108/BFJ-02-2019-0131

Jalilvand, M. R., Khazaei Pool, J., Khodadadi, M., \& Sharifi, M. (2019). Information technology competency and knowledge management in the hospitality industry service supply chain. Tourism Review, 74(4), 872-884. doi:10.1108/TR-04-2018-0054 
Jeffers, P. I., Muhanna, W. A., \& Nault, B. R. (2008). Information Technology and Process Performance: An Empirical Investigation of the Interaction Between IT and Non-IT Resources*. Decision Sciences, 39(4), 703-735. doi:10.1111/j.1540-5915.2008.00209.x

Ji, P., Yan, X., \& Yu, G. (2019). The impact of information technology investment on enterprise financial performance in China. Chinese Management Studies, 14(3), 529-542. doi:10.1108/CMS-04-2019-0123

Johannessen, J., Olaisen, J., \& Olsen, B. (1999). Strategic use of information technology for increased innovation and performance. Information Management \& Computer Security, 7(1), 5-22. doi:10.1108/09685229910255133

Kauffman, R. J., \& Weill, P. (1989). An evaluative framework for research on the performance effects of information technology investment. Proceedings of the Tenth International Conference on Information Systems - ICIS '89, 377-388. doi:10.1145/75034.75066

Kim, C., \& Davidson, L. F. (2004). The effects of IT expenditures on banks' business performance: Using a balanced scorecard approach. Managerial Finance, 30(6), 28-45. doi:10.1108/03074350410769100

Kim, J. K., Xiang, J. Y., \& Lee, S. (2009). The impact of IT investment on firm performance in China: An empirical investigation of the Chinese electronics industry. Technological Forecasting and Social Change, 76(5), 678-687. doi:10.1016/j.techfore.2008.03.008

Kleis, L., Chwelos, P., Ramirez, R. V., \& Cockburn, I. (2012). Information Technology and Intangible Output: The Impact of IT Investment on Innovation Productivity. Information Systems Research, 23(1), 42-59. doi:10.1287/ isre. 1100.0338

Ko, M., \& Osei-Bryson, K.-M. (2004). Using regression splines to assess the impact of information technology investments on productivity in the health care industry. Information Systems Journal, 14(1), 43-63. doi:10.1111/ j.1365-2575.2004.00160.x

Kobelsky, K. W., Richardson, V. J., Smith, R. E., \& Zmud, R. W. (2008). Determinants and Consequences of Firm Information Technology Budgets. The Accounting Review, 83(4), 957-995. doi:10.2308/accr.2008.83.4.957

Kohli, R., \& Devaraj, S. (2003). Measuring information technology payoff: A meta-analysis of structural variables in firm-level empirical research. Information Systems Research, 14(2), 127-145. doi:10.1287/isre.14.2.127.16019

Kohli, R., \& Devaraj, S. (2004). Contribution of institutional DSS to organizational performance: Evidence from a longitudinal study. Decision Support Systems, 37(1), 103-118. doi:10.1016/S0167-9236(02)00211-7

Kohli, R., \& Grover, V. (2008). Business Value of IT: An Essay on Expanding Research Directions to Keep up with the Times. Journal of the Association for Information Systems, 9(1), 23-39. doi:10.17705/1jais.00147

Kraemer, K. L., Gibbs, J., \& Dedrick, J. (2005). Impacts of Globalization on E-Commerce Use and Firm Performance: A Cross-Country Investigation. The Information Society, 21(5), 323-340. doi:10.1080/01972240500253350

Kwon, M. J., \& Stoneman, P. (1995). The Impact Of Technology Adoption On Firm Productivity *. Economics of Innovation and New Technology, 3(3-4), 219-234. doi:10.1080/10438599500000004

Lee, J. J.-Y. (2008). Complementary effects of information technology investment on firm profitability: The functional forms of the complementarities. Information Systems Management, 25(4), 364-371. doi:10.1080/10580530802384761

Lee, O.-K., Sambamurthy, V., Lim, K. H., \& Wei, K. K. (2015). How Does IT Ambidexterity Impact Organizational Agility? Information Systems Research, 26(2), 398-417. doi:10.1287/isre.2015.0577

Li, L. (2005). Assessing intermediate infrastructural manufacturing decisions that affect a ðrm's market performance. International Journal of Production Research, 43(12), 2537-2551. doi:10.1080/00207540500045675

Li, Y., \& Huang, J. (2012). Risk and return of IT investment: Evidence from SCM and CRM announcements. International Journal of Networking and Virtual Organisations, 11(3/4), 290. doi:10.1504/IJNVO.2012.048911

Liang, T., You, J., \& Liu, C. (2010). A resource-based perspective on information technology and firm performance: A meta analysis. Industrial Management \& Data Systems, 110(8), 1138-1158. doi:10.1108/02635571011077807

Lim, J.-H., Dehning, B., Richardson, V. J., \& Smith, R. E. (2011). A Meta-Analysis of the Effects of IT Investment on Firm Financial Performance. Journal of Information Systems, 25(2), 145-169. doi:10.2308/isys-10125 
Liu, H., Ke, W., Wei, K. K., \& Hua, Z. (2013). The impact of IT capabilities on firm performance: The mediating roles of absorptive capacity and supply chain agility. Decision Support Systems, 54(3), 1452-1462. doi:10.1016/j. dss.2012.12.016

Liu, S., Chan, F. T. S., Yang, J., \& Niu, B. (2018). Understanding the effect of cloud computing on organizational agility: An empirical examination. International Journal of Information Management, 43, 98-111. doi:10.1016/j. ijinfomgt.2018.07.010

Liu, S., Yang, Y., Qu, W. G., \& Liu, Y. (2016). The business value of cloud computing: The partnering agility perspective. Industrial Management \& Data Systems, 116(6), 1160-1177. doi:10.1108/IMDS-09-2015-0376

Lu, . (2011). Understanding the Link Between Information Technology Capability and Organizational Agility: An Empirical Examination. Management Information Systems Quarterly, 35(4), 931. doi:10.2307/41409967

Lyver, M. J., \& Lu, T.-J. (2018). Sustaining innovation performance in SMEs: Exploring the roles of strategic entrepreneurship and IT capabilities. Sustainability (Switzerland), 10(2), 442. Advance online publication. doi:10.3390/su10020442

Macher, J. T., \& Mowery, D. C. (2009). Measuring Dynamic Capabilities: Practices and Performance in Semiconductor Manufacturing. British Journal of Management, 20, S41-S62. doi:10.1111/j.14678551.2008.00612.x

Mahmood, M. A., \& Mann, G. J. (1993a). Impact of information technology investment: An empirical assessment. Accounting Management and Information Technologies, 3(1), 23-32. doi:10.1016/0959-8022(93)90007-S

Mahmood, M. A., \& Mann, G. J. (1993b). Measuring the organizational impact of information technology investment: An exploratory study. Journal of Management Information Systems, 10(1), 97-122. doi:10.1080/ 07421222.1993 .11517992

Mao, H., Liu, S., Zhang, J., Zhang, Y., \& Gong, Y. (2020). Information technology competency and organizational agility: Roles of absorptive capacity and information intensity. Information Technology \& People. Advance online publication. doi:10.1108/ITP-12-2018-0560

Marshall, T. E., \& Byrd, T. A. (1997). Relating information technology investment to organizational performance: A causal model analysis. Omega, 25(1), 43-56. doi:10.1016/S0305-0483(96)00040-0

Masli, A., Richardson, V. J., Sanchez, J. M., \& Smith, R. E. (2011). The business value of IT: A synthesis and framework of archival research. Journal of Information Systems, 25(2), 81-116. doi:10.2308/isys-10117

Masli, A., Richardson, V. J., Sanchez, J. M., \& Smith, R. E. (2011). Returns to IT excellence: Evidence from financial performance around information technology excellence awards. International Journal of Accounting Information Systems, 12(3), 189-205. doi:10.1016/j.accinf.2010.10.001

Mcguckin, R. H., Streitwieser, M. L., \& Doms, M. (1998). The Effect Of Technology Use On Productivity Growth. Economics of Innovation and New Technology, 7(1), 1-26. doi:10.1080/10438599800000026

Melville, K., Kraemer, , \& Gurbaxani, . (2004). Review: Information Technology and Organizational Performance: An Integrative Model of IT Business Value. Management Information Systems Quarterly, 28(2), 283. doi: $10.2307 / 25148636$

Menon, N. M., Yaylacicegi, U., \& Cezar, A. (2009). Differential Effects of the Two Types of Information Systems: A Hospital-Based Study. Journal of Management Information Systems, 26(1), 297-316. doi:10.2753/ MIS0742-1222260111

Min, H. (2019). Blockchain technology for enhancing supply chain resilience. Business Horizons, 62(1), 35-45. doi:10.1016/j.bushor.2018.08.012

Mishra, P. C., Kishore, S., \& Shivani, S. (2018). The Role of Information Technology for Knowledge Management: An Empirical Study of the Indian Coal Mining Industry. Journal of Global Information Technology Management, 21(3), 208-225. doi:10.1080/1097198X.2018.1498275

Mithas, S., Krishnan, M. S., \& Fornell, C. (2016). Information technology, customer satisfaction, and profit: Theory and evidence. Information Systems Research, 27(1), 166-181. doi:10.1287/isre.2015.0609 
Mithas, S., Ramasubbu, N., \& Sambamurthy, V. (2011). How information management capability influences firm performance. MIS Quarterly: Management Information Systems, 35(1), 237-256. doi:10.2307/23043496

Mithas, S., Tafti, A., Bardhan, I., \& Goh, J. M. (2012). Information technology and firm profitability: Mechanisms and empirical evidence. MIS Quarterly: Management Information Systems, 36(1), 205-224. doi: $10.2307 / 41410414$

Morkunas, V. J., Paschen, J., \& Boon, E. (2019). How blockchain technologies impact your business model. Business Horizons, 62(3), 295-306. doi:10.1016/j.bushor.2019.01.009

Mukhopadhyay, T., Kekre, S., \& Kalathur, S. (1995). Business Value of Information Technology: A Study of Electronic Data Interchange. Management Information Systems Quarterly, 19(2), 137. doi:10.2307/249685

Nakata, C., Zhu, Z., \& Kraimer, M. L. (2008). The complex contribution of information technology capability to business performance. Journal of Managerial Issues, 20(4), 485-506.

Ong, C.-S., \& Chen, P.-Y. (2016). A valuation model for information technology capability-enabled firm value. Journal of Computer Information Systems, 56(2), 137-144. doi:10.1080/08874417.2016.1117375

Ordanini, A., \& Rubera, G. (2010). How does the application of an IT service innovation affect firm performance? A theoretical framework and empirical analysis on e-commerce. Information \& Management, 47(1), 60-67. doi:10.1016/j.im.2009.10.003

Otim, S., Dow, K., Grover, V., \& Wong, J. (2012). The impact of information technology investments on downside risk of the firm: Alternative measurement of the business value of IT. Journal of Management Information Systems, 29(1), 159-194. doi:10.2753/MIS0742-1222290105

Paré, G., Bourdeau, S., Marsan, J., Nach, H., \& Shuraida, S. (2008). Re-examining the causal structure of information technology impact research. European Journal of Information Systems, 17(4), 403-416. doi:10.1057/ ejis.2008.34

Pérez-López, S., \& Alegre, J. (2012). Information technology competency, knowledge processes and firm performance. Industrial Management \& Data Systems, 112(4), 644-662. doi:10.1108/02635571211225521

Peslak, A. R. (2003). A firm level study of information technology productivity using financial and market based measures. Journal of Computer Information Systems, 43(4), 72-80.

Phama, T. L., \& Jordanb, E. (2009). Information technology resources and business performance: An Australian context. Asia Pacific Management Review, 14(4), 407-426.

Piccoli, G., \& Ives, B. (2005). IT-dependent strategic initiatives and sustained competitive advantage: A review and synthesis of the literature. Management Information Systems Quarterly, 29(4), 747-776. doi:10.2307/25148708

Polykarpou, S., Barrett, M., Oborn, E., Salge, O., Antons, D., \& Kohli, R. (2018). Justifying health IT investments: A process model of framing practices and reputational value. Information and Organization, 28(4), 153-169. doi:10.1016/j.infoandorg.2018.10.003

Purnama, C., \& Subroto, W. T. (2016). Competition intensity, uncertainty environmental on the use of information technology and its impact on business performance small and medium enterprises. International Review of Management and Marketing, 6(4), 984-992.

Radhakrishnan, A., Zu, X., \& Grover, V. (2008). A process-oriented perspective on differential business value creation by information technology: An empirical investigation. Omega, 36(6), 1105-1125. doi:10.1016/j. omega.2006.06.003

Ravichandran, T., Han, S., \& Hasan, I. (2009). Effects of institutional pressures on information technology investments: An empirical investigation. IEEE Transactions on Engineering Management, 56(4), 677-691. doi:10.1109/TEM.2009.2032037

Ravichandran, T., Lertwongsatien, C., \& Lertwongsatien, C. (2005). Effect of Information Systems Resources and Capabilities on Firm Performance: A Resource-Based Perspective. Journal of Management Information Systems, 21(4), 237-276. doi:10.1080/07421222.2005.11045820 
Ray, G., Muhanna, W. A., \& Barney, J. B. (2005). Information technology and the performance of the customer service process: A resource-based analysis. MIS Quarterly: Management Information Systems, 29(4), 625-652. doi: $10.2307 / 25148703$

Razalli, M. R., Hasnan, N., \& Noordin, A. (2017). Business process reengineering and quality performance in the islamic banks: The information technology as a moderator. International Journal of Supply Chain Management, 6(3), 300-308.

Rouhani, S., Ashrafi, A., Ravasan, A. Z., \& Afshari, S. (2016). The impact model of business intelligence on decision support and organizational benefits. Journal of Enterprise Information Management, 29(1), 19-50. doi:10.1108/JEIM-12-2014-0126

Sabherwal, R., \& Jeyaraj, A. (2015). Information technology impacts on firm performance: An extension of Kohli and Devaraj (2003). Management Information Systems Quarterly, 39(4), 809-836. doi:10.25300/ MISQ/2015/39.4.4

Sabherwal, R., Sabherwal, S., Havakhor, T., \& Steelman, Z. (2019). How does strategic alignment affect firm performance? The roles of information technology investment and environmental uncertainty1. MIS Quarterly: Management Information Systems, 43(2), 453-474. doi:10.25300/MISQ/2019/13626

Sabyasachi, M. (2005). Information Technology as an Enabler of Growth in Firms: An Empirical Assessment. Journal of Management Information Systems, 22(2), 279-300. doi:10.1080/07421222.2005.11045847

Salge, T. O., Kohli, R., \& Barrett, M. (2015). Investing in information systems: On the behavioral and institutional search mechanisms underpinning hospitals' is investment decisions. MIS Quarterly: Management Information Systems, 39(1), 61-89. doi:10.25300/MISQ/2015/39.1.04

Sánchez-Rodríguez, C., Dewhurst, F. W., \& Rafael Martínez-Lorente, A. (2006). IT use in supporting TQM initiatives: An empirical investigation. International Journal of Operations \& Production Management, 26(5), 486-504. doi:10.1108/01443570610659874

Santhanam, , \& Hartono, . (2003). Issues in Linking Information Technology Capability to Firm Performance. Management Information Systems Quarterly, 27(1), 125. doi:10.2307/30036521

Schryen, G. (2010). Preserving Knowledge on IS Business Value: What Literature Reviews Have Done. Business \& Information Systems Engineering, 2(4), 233-244. doi:10.1007/s12599-010-0111-y

Schryen, G. (2013). Revisiting IS business value research: What we already know, what we still need to know, and how we can get there. European Journal of Information Systems, 22(2), 139-169. doi:10.1057/ejis.2012.45

Senadheera, V., Warren, M., \& Leitch, S. (2011). A study into how Australian banks use social media. Academic Press.

Shahzad, F., Du, J., Khan, I., Shahbaz, M., Murad, M., \& Khan, M. A. S. (2020). Untangling the influence of organizational compatibility on green supply chain management efforts to boost organizational performance through information technology capabilities. Journal of Cleaner Production, 266, 122029. Advance online publication. doi:10.1016/j.jclepro.2020.122029

Shin, N. (2006). The impact of information technology on the financial performance of diversified firms. Decision Support Systems, 41(4), 698-707. doi:10.1016/j.dss.2004.10.003

Soh, C., \& Markus, M. L. (1995). How IT Creates Business Value: A Process Theory Synthesis. Academic Press.

Soto-Acosta, P., Popa, S., \& Martinez-Conesa, I. (2018). Information technology, knowledge management and environmental dynamism as drivers of innovation ambidexterity: A study in SMEs. Journal of Knowledge Management, 22(4), 824-849. doi:10.1108/JKM-10-2017-0448

Srimarut, T., \& Mekhum, W. (2020). The impact of compatibility on the process integration of the supply chain in improving firm performance: The mediating effect of information technology capability. International Journal of Supply Chain Management, 9(1), 155-167.

Sriram, V., \& Stump, R. (2004). Information technology investments in purchasing: An empirical investigation of communications, relationship and performance outcomes. Omega, 32(1), 41-55. doi:10.1016/j.omega.2003.09.008 
Steelman, Z. R., Havakhor, T., Sabherwal, R., \& Sabherwal, S. (2019). Performance consequences of information technology investments: Implications of emphasizing new or current information technologies. Information Systems Research, 30(1), 204-218. doi:10.1287/isre.2018.0798

Stratopoulos, T., \& Dehning, B. (2000). Does successful investment in information technology solve the productivity paradox? Information \& Management, 38(2), 103-117. doi:10.1016/S0378-7206(00)00058-6

Sun, J., Song, S., Wipawayangkool, K., \& Oh, J. S. (2019). Roles of dynamic capabilities and knowledge management strategies on organizational performance. Information Development. Advance online publication. doi:10.1177/0266666919894377

Tallon, P. P. (2008). Inside the adaptive enterprise: An information technology capabilities perspective on business process agility. Information Technology Management, 9(1), 21-36. doi:10.1007/s10799-007-0024-8

Tallon, P. P., Kraemer, K. L., \& Gurbaxani, V. (2000). Executives' Perceptions of the Business Value of Information Technology: A Process-Oriented Approach. Journal of Management Information Systems, 16(4), 145-173. do i: $10.1080 / 07421222.2000 .11518269$

Tam, K. Y. (1998). The Impact of Information Technology Investments on Firm Performance and Evaluation: Evidence from Newly Industrialized Economies. Information Systems Research, 9(1), 85-98. doi:10.1287/ isre.9.1.85

Tanriverdi. (2006). Performance Effects of Information Technology Synergies in Multibusiness Firms. MIS Quarterly, 30(1), 57. 10.2307/25148717

Teece, D. J., Pisano, G., \& Shuen, A. (1997). Dynamic capabilities and strategic management. Strategic Management Journal, 18(7), 509-533. doi:10.1002/(SICI)1097-0266(199708)18:7<509::AID-SMJ882>3.0.CO;2-Z

Thakurta, R., \& Guha Deb, S. (2018). IS/IT investments and firm performance: Indian evidence. Journal of Global Information Technology Management, 21(3), 188-207. doi:10.1080/1097198X.2018.1498274

Thouin, M. F., Hoffman, J. J., \& Ford, E. W. (2008). The effect of information technology investment on firmlevel performance in the health care industry. Health Care Management Review, 33(1), 60-68. doi:10.1097/01. HMR.0000304491.03147.06 PMID:18091445

Tornatzky, L. G., Fleischer, M., \& Chakrabarti, A. K. (1990). The processes of technological innovation (Vol. 273). Lexington Books Lexington.

Trainor, K. J., Rapp, A., Beitelspacher, L. S., \& Schillewaert, N. (2011). Integrating information technology and marketing: An examination of the drivers and outcomes of e-Marketing capability. Industrial Marketing Management, 40(1), 162-174. doi:10.1016/j.indmarman.2010.05.001

Trieu, V.-H. (2017). Getting value from Business Intelligence systems: A review and research agenda. Decision Support Systems, 93, 111-124. doi:10.1016/j.dss.2016.09.019

Vinekar, V., \& Teng, J. T. (2012). IT impacts in information and physical product industries. Journal of Computer Information Systems, 53(1), 65-71.

Wade, M., \& Hulland, J. (2004). The resource-based view and information systems research: Review, extension, and suggestions for future research. Management Information Systems Quarterly, 28(1), 107-142. doi: $10.2307 / 25148626$

Walsh, G., Schubert, P., \& Jones, C. (2010). Enterprise system investments for competitive advantage: An empirical study of Swiss SMEs. European Management Review, 7(3), 180-189. doi:10.1057/emr.2010.12

Wan, Z., Fang, Y., \& Wade, M. (2007). A Ten-Year Odyssey of the 'IS Productivity Paradox'-A Citation Analysis (1996-2006). Academic Press.

Wang, T., Wang, Y., \& McLeod, A. (2018). Do health information technology investments impact hospital financial performance and productivity? International Journal of Accounting Information Systems, $28,1-13$. doi:10.1016/j.accinf.2017.12.002

Wang, Y., \& Byrd, T. A. (2017). Business analytics-enabled decision-making effectiveness through knowledge absorptive capacity in health care. Journal of Knowledge Management, 21(3), 517-539. doi:10.1108/JKM-082015-0301 
Wang, Y., Shi, S., Nevo, S., Li, S., \& Chen, Y. (2015). The interaction effect of IT assets and IT management on firm performance: A systems perspective. International Journal of Information Management, 35(5), 580-593. doi:10.1016/j.ijinfomgt.2015.06.006

Ward, J., \& Daniel, E. (2012). Benefits management: How to increase the business value of your IT projects (2nd ed.). John Wiley \& Sons. doi:10.1002/9781119208242

Weill, P. (1992). The Relationship Between Investment in Information Technology and Firm Performance: A Study of the Valve Manufacturing Sector. Information Systems Research, 3(4), 307-333. doi:10.1287/isre.3.4.307

Wijayana, S., \& Achjari, D. (2019). Market reaction to the announcement of an information technology investment: Evidence from Indonesia. Information \& Management. Advance online publication. doi:10.1016/j. im.2019.103248

Wu, J., Wang, N., \& Wang, Z. (2017). Impact of information technology capability on financial performance during the period of economic downturn: The case of Chinese listed companies. Electronic Commerce Research, 17(3), 403-423. doi:10.1007/s10660-016-9248-1

Xue, R., Ray, , \& Sambamurthy, . (2012). Efficiency or Innovation: How Do Industry Environments Moderate the Effects of Firms' IT Asset Portfolios? Management Information Systems Quarterly, $36(2), 509$. doi:10.2307/41703465

Yao, L. J., Liu, C., \& Chan, S. H. (2010). The influence of firm specific context on realizing information technology business value in manufacturing industry. International Journal of Accounting Information Systems, 11(4), 353-362. doi:10.1016/j.accinf.2010.09.007

Yao, L. J., Sutton, S. G., \& Chan, S. H. (2009). Wealth creation from information technology investments using the eva $\rightarrow$. Journal of Computer Information Systems, 50(2), 42-48.

Yeh, C.-H., Lee, G.-G., \& Pai, J.-C. (2012). How information system capability affects e-business information technology strategy implementation: An empirical study in Taiwan. Business Process Management Journal, 18(2), 197-218. doi:10.1108/14637151211225171

Zhang, M., Sarker, S., \& Sarker, S. (2013). Drivers and export performance impacts of IT capability in 'bornglobal' firms: A cross-national study: IT capability in 'born-global' firms. Information Systems Journal, 23(5), 419-443. doi:10.1111/j.1365-2575.2012.00404.x

Zhu, K. (2004). The Complementarity of Information Technology Infrastructure and E-Commerce Capability: A Resource-Based Assessment of Their Business Value. Journal of Management Information Systems, 21(1), 167-202. doi:10.1080/07421222.2004.11045794

Zhu, K., \& Kraemer, K. L. (2002). e-Commerce Metrics for Net-Enhanced Organizations: Assessing the Value of e-Commerce to Firm Performance in the Manufacturing Sector. Information Systems Research, 13(3), $275-295$. doi:10.1287/isre.13.3.275.82

\section{ENDNOTE}

IS research has used the term 'Information System (IS)' interchangeably with 'Information Technology (IT)', and 'Information and Communication Technology (ICT)' (Schryen, 2013). In this research, a 'holistic' view on IS has been adopted, as suggested in the ATIS Telecom Glossary: The entire infrastructure, organization, personnel, and components for the collection, processing, storage, transmission, display, dissemination, and disposition of information. In line with this definition, and for consistency, we label IT and ICT as IS throughout the text. 


\section{APPENDIX}

Appendices are available from the link:

https://github.com/zareahad/ISBV/blob/main/Appendices.pdf

Ahad ZareRavasan is an Assistant Professor at the Faculty of Economics and Administration, Masaryk University, Brno, Czech Republic. His publications appeared in acclaimed journals, such as the International Journal of Information Management, Expert Systems with Applications, Information Systems, International Journal of Production Research, Journal of Business and Industrial Marketing, and Journal of Enterprise Information Management. His research interests include IS business value, Business Analytics and Blockchain.

Michal Krčál is an Assistant Professor at the Faculty of Economics and Administration, Masaryk University, Brno, Czech Republic. His doctoral research focused on information system business value and used qualitative methodology (SLR, content analysis, grounded theory coding). 